\title{
Energy and comfort assessment in educational building: case study in a French university campus
}

\author{
Y. Allab ${ }^{1,5^{*}}$, M. Pellegrino ${ }^{2,5}$, X. Guo ${ }^{3,5}$, E. Nefzaoui ${ }^{3,4,5}$, A. Kindinis ${ }^{1,5}$ \\ ${ }^{1}$ Université Paris-Est, Institut de Recherche en Constructibilité, ESTP, 28, avenue du Président Wilson, 94230 Cachan, France. \\ 2 University of Paris-East Marne-la-Vallée, Lab'Urba-GU, Cité Descartes, 5 Boulevard Descartes, 77420 Champs-sur-Marne, France. \\ ${ }^{3}$ ESIEE Paris, Université Paris-Est, 2 Bd Blaise Pascal, 93162 Noisy-le-Grand Cedex, France. \\ 4 Université Paris-Est, ESYCOM Lab., 2 Bd Blaise Pascal 93162 Noisy-le-Grand Cedex, France. \\ ${ }^{5}$ Efficacity, 14-20 boulevard Newton, 77447 Marne la Vallée Cedex 2, France. \\ *Corresponding author. Mail: yallab@estp-paris.eu; tel: +33 695291990 ; address : Institut de recherche en constructibilité, Ecole \\ Spéciale des Travaux Publics du bâtiment et de l'industrie, 28 avenue du Président Wilson, 94230, Cachan, France.
}

\begin{abstract}
The existing stock of institutional buildings constructed before current thermal regulation codes is known to be high-energy consuming. To make energy savings, retrofitting solutions have to deal with important transformations of those buildings (e.g. envelope, energy systems) and with better-suited management solutions. Such technical solutions quite often neglect occupants' comfort. The present work aims to develop and implement an energy audit protocol to tackle simultaneously the questions of thermal comfort and energy efficiency for higher education buildings. Our transverse approach allowed us to achieve a complementary view of the building under examination, including its operating conditions. At any rate, capturing the full complexity of a building-system (building energy devices, management strategies, and occupancy and behaviours impacts) requires a broad perspective and points to the limits of key-in-hand audits and solutions.
\end{abstract}

Keywords: educational building, energy audit, thermal comfort, indoor air quality

\section{Introduction}

Nowadays, the building sector remains one of the largest energy consumer with more than $40 \%$ of final energy consumption in the European community [1] and represents obviously a key sector regarding energy savings and decarbonisation opportunities. Indeed, in addition to the energy efficiency measures, the European Commission (COM/ 2011/ 885 Energy Roadmap 2050) has defined strict long term goals with $80 \%$ decarbonisation by 2050 [2]. On the other hand, the growing interest for users comfort and well-being implies an increasing focus on the definition and assessment of micro-climatic requirements. Users comfort regarding IEQ (indoor environmental quality) which implies IAQ (indoor air quality), thermal, visual and acoustic 
comfort is considered as "an integral part of the total building performance approach" [3] and is inevitably linked to the energy performance. Viewed from this perspective, the operation and maintenance of a building are as important as the design phase because energy efficiency and comfort are strictly related to the building operating conditions [1]. Therefore, a suitable assessment and monitoring of the building performance both in terms of energy and IEQ is necessary for the user to achieve satisfactory levels of comfort with minimum consumption of energy resources.

Educational buildings i.e school buildings and university campuses are particularly concerned by the issues of energy and IEQ and require more attention because of their specific character compared to other buildings. In fact, educational buildings represent a special case mainly because of their specific occupants, activities and occupancy pattern.

Knowing that children and/or students spend around $25 \%$ of their time at school [4], educational buildings are a good opportunity to promote building energy efficiency and environmental quality towards the pupils and their families $[5 ; 6]$. This issue leads to several projects and programs in educational area as Renewschool [7] a European project focusing on the improvement of energy efficiency and IEQ in schools and as the Alliance K-12 which groups a number of programs to change the culture of students' academic environment toward energy efficiency [8].

Besides the educational and ethical issues, educational buildings offer a good opportunity for energy savings. Energy represents the second higher expense in schools after the payroll [5]. In addition, because of their large number in each country, educational buildings are a large energy consumer. For instance, they cost around 6 billion \$/year in the US [8]. In addition, as stated above, it should be noted that educational buildings require special attention on monitoring conditions and building system management because of their particular occupancy and schedule. Indeed, a study conducted by D.F Cabrera et al. [9] showed the impact of occupancy on energy savings on lighting in an educational building. Based on an in-field data analysis, the authors demonstrated a clear impact of lighting control on energy consumption and proposed an improvement based on a methodology for discovering energy waste patterns related to lighting.

Finally, when it comes to IEQ issues, educational buildings are of primary concern in the building sector. Moreover, IEQ in educational buildings may be more important than energy efficiency issues. In tertiary buildings, a number of studies showed the benefits of ensuring IEQ to improve 
workers' productivity [10;11; 12]. El Asmar [13] pointed out the economic impact that IEQ can have "Since the cost of employees in doing business is substantially higher than the cost of energy, workplace designers need to provide workers with environment as comfortable and productive as possible through improved IAQ and thermal comfort." In educational buildings, if one considers the IEQ effect on health and performances of occupants, the costs of a good IEQ seem lower than the achieved IEQ [6].

As reported above, the knowledge on building performance assessment is nowadays necessary and crucial to guarantee suitable IEQ in energy efficient buildings. Over the last decades, a number of studies have proven the success of in situ assessment especially for energy audits to apply energy efficiency measures [9; 14; 15]. In fact, energy and IEQ audits contribute to identify the building weaknesses and provide potential improvements. From the above considerations, it is clear that improving and implementing audits on educational building is substantial.

The present paper describes a study conducted on a French university campus. The study consists in adapting and implementing an audit protocol including simultaneously energy efficiency and indoor climate quality (thermal comfort and indoor air quality) issues. In addition, the study was conducted to address two main issues: i) the lack of knowledge and data on energy and IEQ in French educational buildings; ii) the need for protocols and benchmarks to assess IEQ and energy efficiency in educational buildings. The proposed protocol was implemented on a case study, an engineering school campus for instance, in the region of Paris between January and July 2015. Most of the results are case specific but the proposed methods can be generalized and implemented on other buildings of the same kind.

The present paper is constructed as follows: after a brief literature review, the objectives, the case study as well as the global process are presented in section 3. Then, each task of the performed audit is detailed. The obtained results at each step of the implemented protocol are presented and discussed individually in section 4. Finally, section 5 reports a discussion of the global process results and methods.

\section{Literature review}

Over the last decades, a number of studies were performed on educational buildings both on energy, IEQ and in a few cases on energy and IEQ simultaneously. Most of them have proven the interest of this kind of studies with regard to several points: a lack of homogeneity of protocols and benchmarks; large consuming buildings and often poor IEQ. 
In France, the city of Paris where schools represent $38 \%$ of the municipal facilities consumptions [16] a program concerning energy efficiency in schools has been launched in 2008 to reduce the consumption by $30 \%$. The program includes more than 600 school buildings constructed between 1880 and 2012. The refurbishment concerned particularly envelopes (insulation and fenestration) and the heating systems. The whole consumption including all energy sources represents on average $225 \mathrm{kWh} / \mathrm{m}^{2} /$ year. The study published by Mairie de Paris [16] on 100 school buildings refurbished in 2012 revealed some expected key values as $10700 \mathrm{MWh}$ economy on final energy; a reduction of $2300 \mathrm{t}$ of carbon dioxide and $85000 €$ saved per year.

In Luxembourg, a study published by [17] shows the results of an energy consumption analysis and potential savings on 68 school buildings. The study revealed that simple solutions as insulation and air tightness can reduce the energy demand. The author estimates a potential saving which represents $1 \%$ of the national annual fuel oil and gas consumption in the tertiary. In Slovenia, a study was conducted by [18] on 24 old schools regarding IEQ and energy efficiency. The study showed poor values in terms of energy consumption with $89 \%$ heat losses over the recommendations. The energy number per pupil during the heating season were estimated to 2.17 MWh while the average energy number for heating was $267 \mathrm{kWh} /\left(\mathrm{m}^{2} . \mathrm{yr}\right)$. In addition, the study revealed lacks with regarding the envelope insulation and fenestration for more than $83 \%$ of the buildings.

Daslacki and Sermpetzoglou [19] presented the results of an energy audit on 135 schools and analysed a number of energy conservation solutions while ensuring acceptable IEQ. The average thermal and electrical consumption were respectively $57.12 \mathrm{kWh} / \mathrm{m}^{2}$ and $29 \mathrm{kWh} / \mathrm{m}^{2}$. The analysis was carried out on three climatic zones with a base temperature for Heating Degree Days (HDD) of $18{ }^{\circ} \mathrm{C}$. The investigation showed that $63 \%$ of the buildings were not thermally insulated while only $23 \%$ had double glazed windows. It also revealed that $43 \%$ of the studied buildings were performing envelope refurbishments (fenestration, mainly), while $24 \%$ and $22 \%$ were concerned by improvements of the heating and the lighting systems, respectively.

A review conducted by Das Perreira [5] on the energy consumption in schools revealed that important gaps in the energy needs are present depending on the educational level (elementary, primary, secondary, etc.). In fact, the author pointed out in the context of the USA that the difference between primary and secondary schools corresponds to $50 \%$ (173 vs $257 \mathrm{kWh} / \mathrm{m}^{2}$, respectively). In the UK, an opposite trend is observed. Indeed, the global energy consumption varies between 177 and $196 \mathrm{kWh} / \mathrm{m}^{2}$ for secondary and primary school, respectively. 
A number of studies were carried out on university campuses (UC) which present different and complex characteristics in comparison with primary or secondary schools as the occupation, the area and the facilities like laboratories. A study was conducted by Duzgun [20] on 24 UC buildings of the University of Florida in the USA including 10 LEED-certified and 14 non-LEED educational buildings on the basis of monthly consumption data for chilled water, steam and electricity for 2013. The results presented by [20] on the basis of mean EUI metric showed a significant difference between the LEED (331.20 kBTU/sf/yr) and non LEED building (222.70 $\mathrm{kBTU} / \mathrm{sf} / \mathrm{yr}$ ). Nevertheless, no significant differences were proven on the basis of the median values of EUI (172.64 for LEED and 178.16 for non LEED). The author concluded that "no clear trends in energy savings of LEED buildings were observed ("both at the portfolio and at individual building level)" [20]. The author recommended focusing on $\mathrm{CO}_{2}$ emissions and the building functionalities.

However, a number of studies showed that UC buildings can be assessed using European standards for individual buildings [21]. A methodology for the assessment of energy efficiency of UC was proposed by Deshko [21] to create an energy certification for UC in Ukraine. The methodology was based on a number of parameters as the operating conditions, the size, the climate zone, and the types of energy sources regarding the efficiency of heat consumption of primary energy. The results highlighted the relevance of the European standards (EN 15217) in Ukraine's UC [21]. Furthermore, they revealed that $58 \%$ of the UC require refurbishments to improve energy efficiency.

IEQ assessment are probably the most common in educational buildings and most of them have proven the big impact of IEQ on occupants. As reported above, besides its relevance to avoid health problems and diseases contamination (particularly linked with thermal comfort and indoor air quality) [22], IEQ can affect students' and teachers' performances [23]. According to [24] the effect of IEQ "has not yet been demonstrated on the performance of simple tasks resembling schoolwork" but the positive effect of IEQ should help "to complete routine exercises more quickly" and "would leave more time for learning, leisure and other school activities" [24]. The same authors showed through a seven surveys study performed on a total of 380 children that poor IEQ can reduce performances by $30 \%$ [24]. Furthermore, educational buildings are strongly characterized by classrooms which are different from other indoor environments. Classrooms are characterized by their high occupancy density (around $1.8 \mathrm{~m}^{2} /$ person) [6]. This factor affects the level of indoor climate quality. In fact, a high occupancy increases the internal 
thermal gains (26 W on average) which can induce a local thermal discomfort $[25 ; 26]$ and, consequently, a decrease in occupant's performance. The influence of temperature on productivity was investigated by [27] on 24 cases of study. The author pointed out a decrease of the productivity around $2 \%$ for each temperature difference of $1^{\circ} \mathrm{C}$, over the comfort temperatures range (above $25^{\circ} \mathrm{C}$ ). When it comes to IAQ, the effect of a high occupancy is even more significant. An experimental study performed in a test cell [28] pointed out the impact of occupancy on indoor $\mathrm{CO}_{2}$ concentration and thus on the IAQ. In fact, Mudarri [29] found out that a sedentary person emits $19 \mathrm{l} / \mathrm{h}$ of $\mathrm{CO}_{2}$ on average. The carbon dioxide concentration is considered as a relevant index according to users' perception of indoor air quality. A recent experimental study showed the effect of carbon dioxide on work performance on the basis of decision making tests and by exposing occupants to various carbon dioxide concentrations [30]. The results showed moderate effects of carbon dioxide concentration on work performances for $1000 \mathrm{ppm}$ and large effects for $2500 \mathrm{ppm}$. Fanger and Berg- Munch [31] researches led to a correlation between the percentage of occupants dissatisfied with indoor air quality and measured $\mathrm{CO}_{2}$ levels. Later, Clausen [32] expressed the correlation between the perceived IAQ and the occupants' time exposure. Bako-Biro [33] showed, through a study on indoor air quality in schools, that inappropriate ventilation rates affect students learning performances. Besides thermal comfort and indoor air quality which are the most studied parameters with regard to occupants' performances during the last decades, some studies investigated the effect of visual comfort on students' performances. Heschong [34] showed through his experiments an improvement of $26 \%$ of reading tests under improved visual comfort conditions.

The impact of IEQ on students' performances leads a number of schools and universities to focus on the assessment of IEQ [13]. Unfortunately, over the last years, a number of studies showed the poor IEQ in schools worldwide $[34 ; 35 ; 1 ; 36]$ and even in developed countries.

A study on 39 Swedish schools revealed that $77 \%$ of the sample did not meet the regulation limits $[37 ; 38]$. A study was conducted on two university campuses in two different countries (USA and Lebanon) on IEQ [13] by means of a questionnaire survey. The results presented by the author showed that both campuses were out of ASHRAE comfort range ( $80 \%$ satisfaction) regarding thermal comfort. A study was conducted in Greece on five school buildings using both subjective and objective evaluation of IEQ [19]. The objective assessment was based on physical parameters measurements related to IEQ while the subjective assessment was based on questionnaire survey. The results showed inappropriate conditions in terms of thermal comfort 
with $60 \%$ of the recorded values out of the comfort range fixed by ASHRAE and CEN, even during spring period while in the same season a third of humidity values were out of comfort range (30-60\%). The indoor air quality assessed on the basis of carbon dioxide concentration was on average $33.7 \%$ out of the upper limit fixed by CEN (850 ppm). The subjective results revealed that $29 \%$ of teachers and $57 \%$ of students were unsatisfied about thermal comfort during summer while $29 \%$ of students complain about thermal comfort in winter. A similar study was carried out by Theodosiou [6] including energy consumption and efficiency measurements. In fact, Theodosiou [6] published the results of an investigation on school buildings in the city of Kozani, in Greece applying a global approach which includes energy assessment, ICQ (thermal comfort and indoor air quality) assessment by measurements and subjective survey. Recently, a study was conducted on the UC of Polytechnic University Timisoara, in Romania including thermal comfort assessment (physical measurements and subjective survey) and IAQ assessment ( $\mathrm{CO}_{2}$ measurements) [39]. Furthermore, the study included an analysis of the effect of IEQ on students' performances by means of tests. Finally, a numerical model of an amphitheatre in the campus including thermal comfort and energy demand was implemented on TRNSYS. Thermal comfort analysis showed good results with a range of mean PMV values between 0.55 and 0.69 while the $\mathrm{CO}_{2}$ values were above the standards limits reaching $2400 \mathrm{ppm}$ on average. The authors suggested improvements of the IAQ (decrease to $1500 \mathrm{ppm}$ ) and thermal comfort (decrease to 0.34 of PMV) by operable windows. The optimal performance temperature was estimated around $27^{\circ} \mathrm{C}$ during the cooling season while the optimal humidity was estimated at $60 \%$.

\section{Methodology}

\subsection{Objectives}

We carried out an energy audit of a higher education building. We were interested in the building and its energy systems operating conditions as well as the occupants' environmental quality. An original audit protocol that simultaneously addresses these two interrelated points was necessary. For this purpose, we set up an energy audit protocol which includes, in addition to the usual diagnostic and modelling of the building envelope and energy systems, comfort surveys (thermal, air quality) and surveys of occupants' practices. Consequently, we can identify several goals in our work depending on the considered point of view: 
- The audit perspective: the first objective was to study the building in relation to its energy consumption. For this purpose, it was necessary to consider the energy management strategies as stated by the managers of the building as well as experimental data to verify the implemented strategies and identify possible problems.

- The standpoint of environmental quality for occupants: we relied on existing protocols based on international standards to draft comfort and air quality surveys. Our goal was two-fold. Indeed, we realized quantitative measurements to identify possible problems (e.g. overheating, excessive levels of $\mathrm{CO}_{2}$, etc.) and conducted surveys with occupants to complete experimental data with subjective information. We also considered the occupants' practices, particularly focusing on energy-intensive practices. Identifying and highlighting the relationship between comfort and energy consumption was a major point during this process.

- Finally, a larger methodological point of view: to set up an original energy audit protocol, combining different and complementary approaches and methods: physical measurements on the building and its energy systems, observation, questionnaires, modelling and simulation. The cross-disciplinary character of the approach should be reflected in the findings: a holistic consideration of the results of the different tasks should allow a clearer understanding of the building operating conditions and should therefore lead to more realistic and accurate recommendations.

\subsection{Description of the global process}

The adopted energy audit process includes two main tasks: an energy audit of the building and its HVAC systems and a thermal comfort survey which were held simultaneously. The building energy audit was performed at two levels: a global level and a local one. In the former, the consumption of the whole building is considered through bills and measurements. In the latter, a representative sample of the building was chosen and instrumented. A set of parameters relative to the HVAC systems and the thermal comfort were measured during a campaign of measurements of several weeks. The measured data were used to validate a dynamic thermal simulation model of the building. The model was then used to quantify the impact of a set of recommendations on the consumption and energy cost of the building. The measurements also revealed poor air quality at high occupation periods. Consequently, additional measurements on the ventilation system performances were implemented to 
investigate different ventilation strategies as candidates for the air quality improvement. A schematic diagram of the audit process is presented in Figure 1.

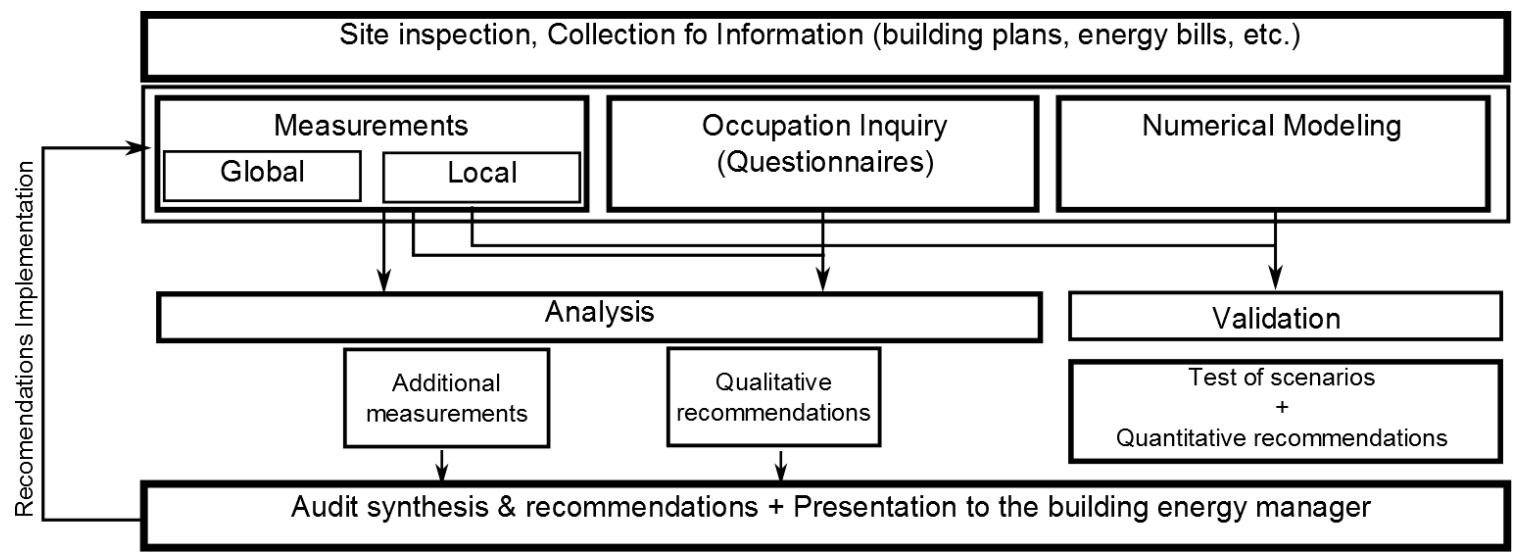

Figure 1. A flowchart of the audit protocol.

The different tasks of the process are described in detail in the following paragraphs.

\subsection{Case study}

Before detailing the different implemented auditing tasks, the case study will be first presented to simplify later references.

The studied site was built in 1987 with a total net floor surface of $30580 \mathrm{~m}^{2}$. The site consists of a central hall, six buildings of 5 floors each, and a gym. The six buildings are all connected to the central hall, as well as the gym.

The site mainly includes teaching rooms of different sizes and administrative offices. Special processes such as clean room facilities and server rooms mainly rely on electricity and their consumption are considered as non-regulated consumptions.

The building indoor environment is regulated by two energy systems: air handling system and a heating floor system. Both systems use hot water as the heat transfer fluid. Under local climate, there is no need for cooling except for special utilities such as the datacenters and the clean room laboratories where conditioned air is needed year-round. The detailed configuration of the buildings, their utilities, as well as their main energy supplies are shown in Figure 2.

Annual energy consumptions (electricity and gas) from 2013 to 2015 have been collected. The energy bills reveal more than three times larger primary energy consumption than a low energy building under the same weather condition but constructed under a recent French building regulation RT2012. Hence a detailed energy audit should help understanding the following issues: i) what is the part of the specific processes in the total energy consumption? ii) how much 
energy consumption can be avoided after appropriate recommendations? iii) does indoor environmental quality match with users' comfort expectations? Emphasis was given to the six buildings since they are more related with human occupation and more concerned by thermal comfort issues. Moreover, the central halls as well as the gym are considered as open space areas, hence with lower comfort-related requirements.

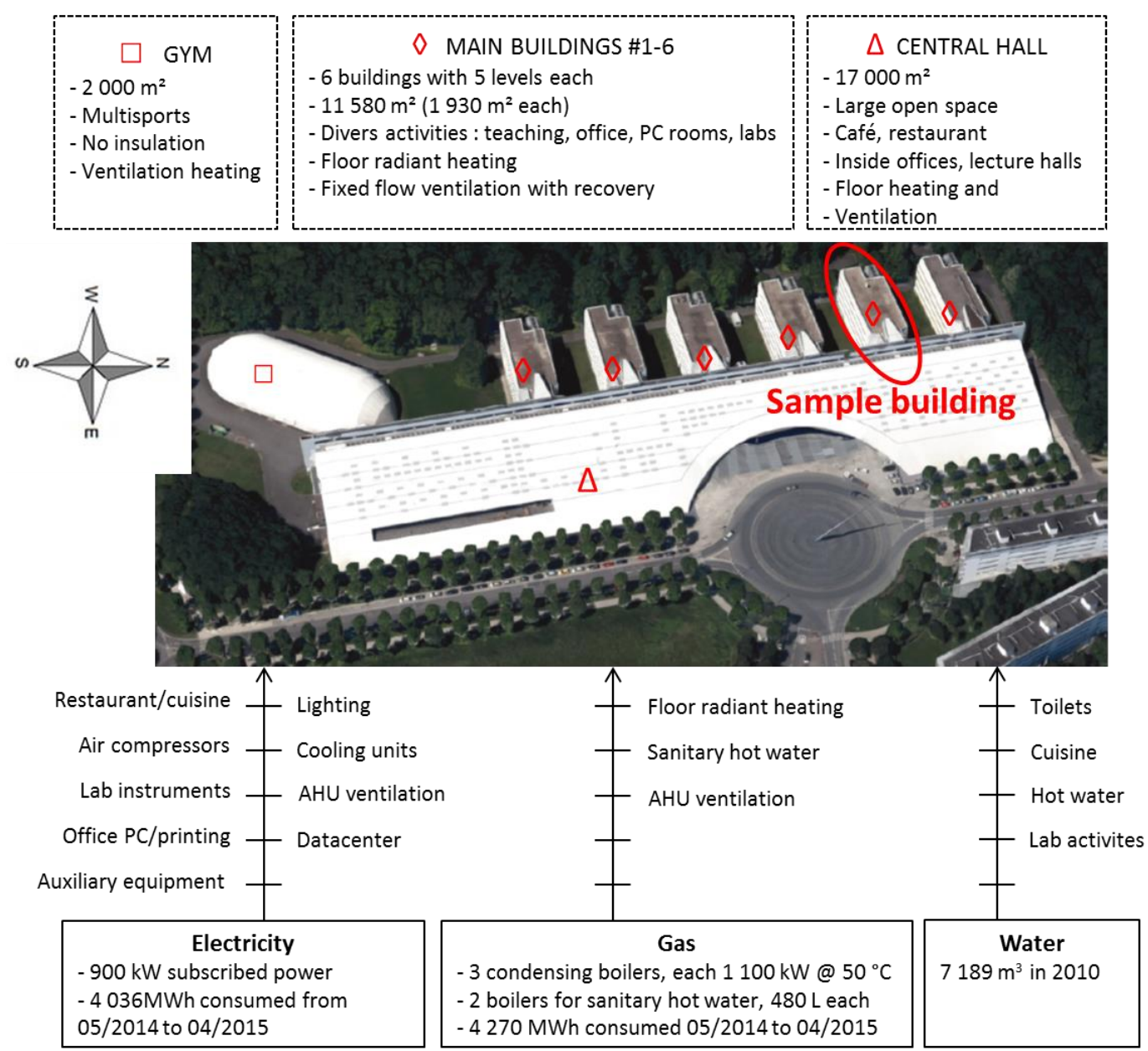

Figure 2. Details of the studied site - buildings, utilities and energy supplies. The red circle indicates the sample considered for instrumentation, measurements and building energy model validation presented in the following sections.

\subsection{Detailed presentation of the specific tasks}

\subsubsection{Inspection and information collection: the building}

The envelope of the building is characterized by the mixed employment of concrete, windows and aluminium supports. Large windows are generally designed especially to the south side. Natural lighting is a trivial advantage of this design. However, it induces larger heat losses through cold bridges. Moreover, high penetration of solar radiation from the south side in 
addition to fluctuating occupancy in classrooms, makes thermal control more difficult since the current control system has little automation.

\subsubsection{Diagnostic: energy systems and supply}

Electricity and gas are the energy sources used in the considered site.

Regarding electricity, the subscription is contracted with a maximal power demand of $900 \mathrm{~kW}$. Extra demand is charged with a higher price per kWh. Off-peak tariff plan during nights and weekends applies too. One general meter is available for the whole site. It gives only a monthly total consumption in kWh. A third part service company (in our case EVELER) was contracted to provide a quasi-real-time total electric consumption every $10 \mathrm{~min}$. Along with its online platform, we are able to follow and interpret the electric consumption during 1 year.

The production of thermal energy is provided by three condensing gas boilers recently renovated (in 2013). Each of them can provide up to $1100 \mathrm{~kW}$ thermal power under full load when producing hot water at $50^{\circ} \mathrm{C}$.

The energy systems between the boilers room and end users consist in air and water systems.

First, the air system consists in Air Handling Units (AHU) with heat recovery between new and return air are operated during occupation. The air systems mainly provide new air into the building but they are also used to provide heating during peak heating load periods.

First, fresh air is preheated in a water-to-air heat exchanger inside the AHU (Air Handling Unit, situated at the top of each of the six buildings), after passing through a recovery unit gaining temperature from return air. The preheated air is generally controlled at $15{ }^{\circ} \mathrm{C}$ before being sent to each floor. Another water-to-air heat exchanger with adjustable water flow rate valve is manually controlled by end users. In the end, the obtained ventilation temperature ranges from $15^{\circ} \mathrm{C}$ to $25^{\circ} \mathrm{C}$.

The adjustment is done by two ways: firstly, operators can control the ON/OFF time through IBMS (Integrated Building Management System); secondly at each floor a thermostat is placed at each face (north and south) of the building. In general, the thermostat is situated in an office around the middle of the corridor at both north and south side. Water temperature into the end heat exchanger is regulated according to this thermometer and the user's regulation.

Second, the water system is a heating floor system. It is controlled by a local substation at the ground floor of each building. The inlet temperature of the heating floor is controlled by the 
mixing between supply and return water, through a thermostat according to outdoor temperature and following a heating curve.

Heat meters are available so that accumulated energy delivered to subsystems such as that of the gym, the central hall and the six buildings can be obtained. Detailed instrumentation and measurement during a period will help understanding the operation principles.

The air and water systems and their regulation can be found in Figure 3.

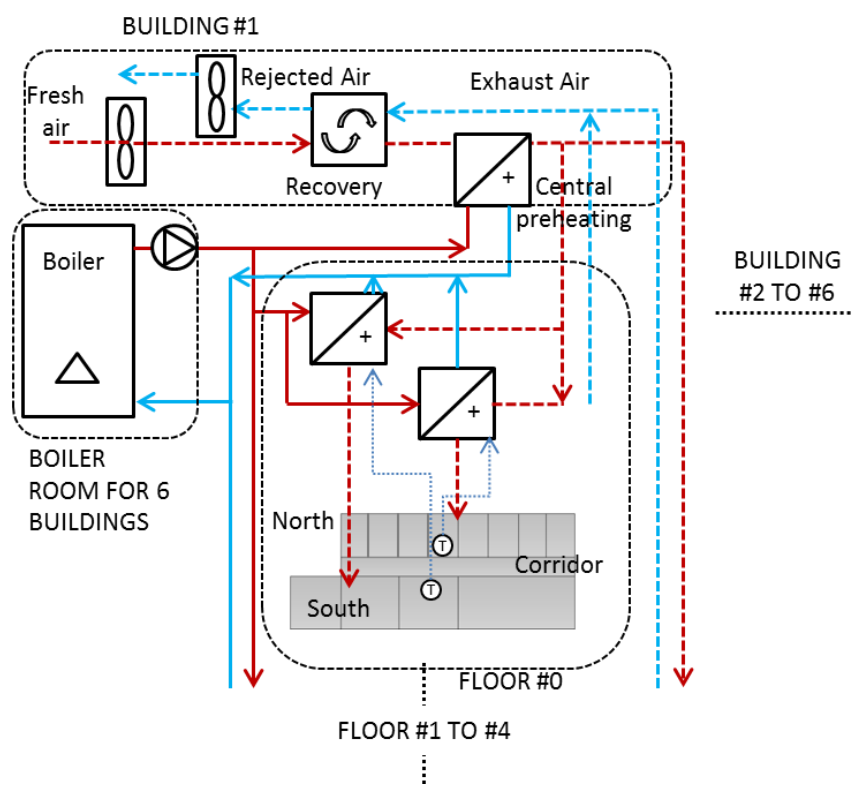

Figure 3. AHU and water systems provide indoor ventilation

At the water side, hot water from the condensing gas boiler is pumped to a substation in each building. At the outlet of each substation, temperature regulated hot water is then circulated through heating floor grills. The substation controls the outlet hot water temperature according to an outdoor temperature sensor under a manual pre-set heating curve. The water system and its control are shown in Figure 4.

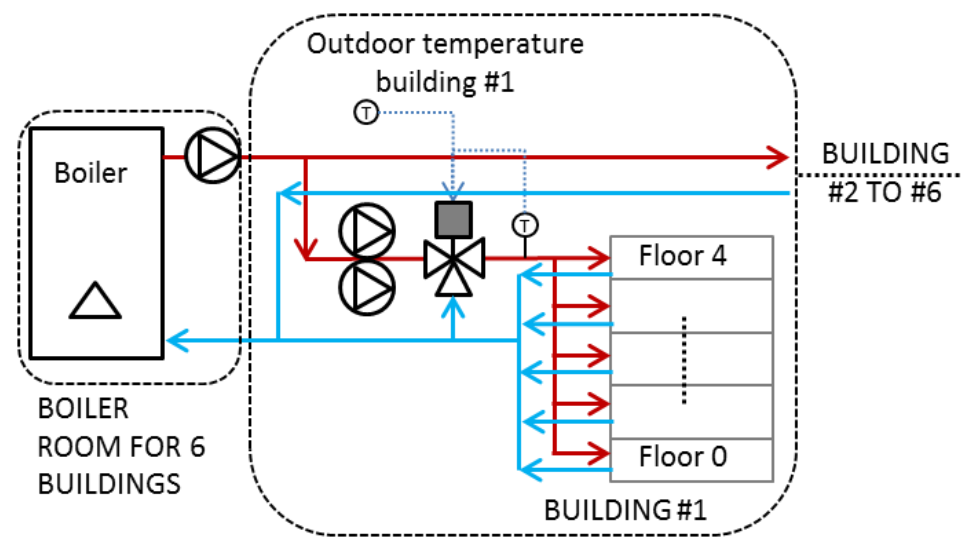

Figure 4 : Heating floor system regulation through substation - structure and heating curves 
It is worth noting that two of the six substations (one per building) were renovated in 2012. The control principle is the same as the initial design. However, differences could appear, regarding sensors precision as well as the controllers. The comparison of the heating characteristics of each substation is in this case interesting and will be presented later.

As explained above, the ventilation is mainly provided by the AHU which aims to guarantee indoor air quality by providing fresh air to the occupants. However, the building is equipped with operable windows which overlap with the mechanical ventilation. Thereby, in addition to the measurements in the AHU for an overall estimation of the whole mechanical ventilation rates, an experimental campaign was conducted to understand the local operation/behaviour of the ventilation system (including natural and mixed mode ventilation) in the occupied zone.

The experimental campaign was conducted on one sample office. This sampling and the ventilation scale analysis were motivated by two main issues: the complexity of the ventilation system and the adopted measurement method. In fact, each office is equipped with mechanical supply vents (and exhaust in the corridor) and two or three operable windows. This can induce various ventilation strategies: natural ventilation (one window or more), mechanical ventilation and mixed mode ventilation (mechanical and natural at the same time). On the other hand, the experimental method adopted (tracer gas measurements) was time consuming and quite expensive but the most used and accurate for the estimation of air change rates and ventilation effectiveness.

To achieve the objective cited above, a methodology based on 3 steps was set: auxiliary measurements; air change rates measurements; ventilation effectiveness measurements.

The auxiliary measurements do not concern the assessment of ventilation but concern the characterization of the experimental conditions i.e. characterization of the studied room and characterization of indoor and outdoor climate conditions.

The characterization of the room is carried out upstream of the measurement tests of the ventilation and implies: the definition of the studied zone' geometry (measures of the volume and the effective surface of openings windows), the characterization of the envelopes' airtightness (blower door test by depression/overpressure); the characterization of the type of ventilation tested (the mechanical ventilation's location of vents, and the windows' location and geometry).

The investigated office is located in the middle of the $2^{\text {nd }}$ floor of building 3 . It is an individual office with an $18 \mathrm{~m}^{2}$ area and a geometrical volume of $51.16 \mathrm{~m}^{3}\left(54.12 \mathrm{~m}^{3}\right.$ including the 
technical space above the false ceiling). The effective volume [40] which is the real volume occupied by the air was estimated by means of pulse injection tracer gas technique, according to the ASTM E741 [41]. It is worth noting that the estimation of the effective volume is crucial when converting air change rate to air flow rate. In fact, using an accurate value of the real volume (effective volume), the uncertainties in the estimation of the air flow rate could be reduced from 4.5 to $14.5 \%$. Thereby, the effective volume of the investigated room was estimated to $49.01 \mathrm{~m}^{3}$. It is equipped with 3 operable windows (as the most of the offices). The windows are manually operable and tilted with an effective opening area of $0.6 \mathrm{~m}^{2}$ for each window while the mechanical vents are in front of the windows, under the false ceiling.

The characterization of climatic conditions was made simultaneously to ventilation measurements by means of a weather station $20 \mathrm{~km}$ from the studied building (air temperature, relative humidity, speed and wind direction). Outdoor $\mathrm{CO}_{2}$ rates were recorded by a data logger on the site. The indoor climatic conditions in the occupied zone and in the zone of interest (operative temperature, relative humidity, air velocity) were measured by an indoor climate station. The characteristics of the indoor climate station (LSI portable thermal environment monitoring system) are presented in Table 1 . The measurements were performed continuously during the tests with a 1-minute time step.

Table 1 : characteristics of instrumentation devices.

\begin{tabular}{|l|l|l|l|l|}
\hline Device & Parameter & Symbol & Measuring range & Accuracy \\
\hline \multirow{2}{*}{$\begin{array}{l}\text { LSI portable thermal } \\
\text { environment monitoring }\end{array}$} & Air temperature & $\mathrm{Ta}_{\mathrm{a}}$ & $-50-70{ }^{\circ} \mathrm{C}$ & $\pm 0.1^{\circ} \mathrm{C}$ \\
\cline { 2 - 5 } & Black globe temperature & $\mathrm{T}_{\mathrm{g}}$ & $-40-80{ }^{\circ} \mathrm{C}$ & $\pm 0.15^{\circ} \mathrm{C}$ \\
\cline { 2 - 5 } & Relative Humidity & $\mathrm{RH}$ & $0-100 \%$ & $\pm 1.5 \%$ \\
\cline { 2 - 5 } & Air velocity & $\mathrm{Va}$ & $0.01-20 \mathrm{~m} / \mathrm{s}$ & $\pm 0.05+0.05 \mathrm{Va} / \mathrm{s}$ \\
\hline Dataloger $\mathrm{KTHCO}_{2}-\mathrm{E}$ & Air temperature & $\mathrm{T}_{\mathrm{a}}$ & $-20-70{ }^{\circ} \mathrm{C}$ & $\pm 0.5{ }^{\circ} \mathrm{C}$ \\
& $\begin{array}{l}\text { Relative Humidity } \\
\text { Carbon dioxide }\end{array}$ & $\mathrm{RH}$ & $0-100 \%$ & $\pm 0.88 \mathrm{RH} \%$ \\
$\mathrm{CO}_{2}$ & $0-5000 \mathrm{ppm}$ & $\pm 50 \mathrm{ppm}$ \\
\hline
\end{tabular}

The measurements of ventilation rates are based on tracer gas techniques as described in [42]. Depending on the gas injection method and on the gas monitoring method, we distinguish 4 main techniques: concentration decay, constant injection, constant concentration and pulse injection. The calculation method (based on the mass balance equation) is presented in $[41 ; 42]$. The ventilation rates could be expressed as air change rates (or air $A E H, h^{-1}$ ) or as air flow rate $\left(\mathrm{m}^{3} / \mathrm{h}\right)$. Both of them could be directly measured with specific techniques. In the present work, 
the concentration decay was adopted to measure the air exchange per hour (AEH) according to the ASTM E741 [41]. The air flow rate was estimated through the measured AEH and the measured effective volume according to Equation 1.

$$
\lambda=\mathrm{Q} / \mathrm{V}
$$

Where $\lambda, Q$ and $V$ are the air exchange per hour, the air flow rate and the effective volume, respectively.

Tracer gas measurements were performed using a multipoint sampler and doser Innova 1303 for the gas monitoring and a Photoacoustic Gas Monitor Innova 1412i for the measurement of the $\mathrm{CO}_{2}$ rates which was used as a tracer gas.

Ventilation effectiveness is measured through parameters as age of the air, residual time and residence time [43]. In the present work, the NORDEST method [44] was used to estimate the ventilation rates, the age of the air and air exchange efficiency. The latter characterizes the ability of the ventilation system to renew the air in the ventilated space. An air exchange efficiency of $50 \%$ corresponds to a mixing ventilation (fresh air totally mixed with the old air) while values smaller than $50 \%$ express the presence of short circuits and dead zones (zones without fresh air) and values over 50\% express a piston flow ventilation [45].

The office was mapped with six measurement points to estimate the spatial variation of the age of the air. As explained above, five ventilation strategies were tested during the two sessions:

- Mechanical ventilation $\left(\mathrm{V}_{\mathrm{M}}\right)$ : local supply vent

- Natural ventilation $\left(\mathrm{V}_{\mathrm{N} 1}\right)$ : single side ventilation through one window

- Natural ventilation $\left(\mathrm{V}_{\mathrm{N} 2}\right)$ : single side ventilation through three windows

- Mixed mode ventilation $\left(\mathrm{V}_{\mathrm{MM}}\right)$ : mechanical ventilation and single side ventilation (one window)

\subsubsection{Thermal comfort and indoor air quality:}

The notion of "comfort" is broad and complex [46; 47; 48; 49; 50; 51]. It is based on subjective evaluations of thermal and acoustic conditions, air quality, visibility, lightening, accessibility, etc. In our study we only address thermal comfort and air quality. We also investigate the link between comfort, practices and uses and energy consumption [52; 53; 54].

The evaluation of indoor thermal comfort requires a rigorous methodology to follow, according to standards $[55,56,57,58,59]$, and reference literature. At a national French level, the 
buildings regulation RT 2012 should be taken into account. Four major steps can be identified: a) cognitive study; b) subjective investigation; c) measurement campaign; d) calculation of indices. The cognitive study represents the preparatory work necessary to fully understand the considered "system-building". It is based on several exploratory visits characterized by the following: observation of the premises; identification of critical areas (mapping); first approaches to occupants concerning uses and comfort; identification of energy consuming behaviour. The subjective investigation may be conducted through interviews vis-à-vis and/or with preestablished questionnaires. The second method was chosen here to have a larger number of responses and a quantitative evaluation of thermal comfort, using standardized methods (Thermal sensation vote, thermal preference, etc., as specified by EN ISO 10551 [59]). The questionnaires are therefore a necessary instrument for the assessment of users' behaviour. Thus, they can include questions concerning the realization and the frequency of some energyrelated uses (such as to open and close the window, the door; to use an additional personal heating device or other electronic devices, etc.). Questionnaires are distributed with a brief explanation of the subject and objectives of the survey and after 30 minutes of occupants' permanence in the surveyed space (EN ISO 10551 [59]). This delay is considered necessary to ensure that the response is not influenced by external factors.

The measurement campaign is held at the same time as the distribution of the questionnaires, to obtain a correspondence between objective values (measurements) and subjective responses (questionnaires). The response time of the sensors need to be taken into account in the case of location change. When possible, sensors are placed in the middle of the room. Locations with no direct irradiation are considered.

The calculation of the indices is the data processing part (see section 4.3 for results). They are calculated according to the previously quoted standards.

The indoor air quality assessment was carried out by comparing the measured $\mathrm{CO}_{2}$ concentrations above outdoor level with the limits fixed by EN 15251 [55] standard. Two classrooms were monitored continuously during 2 weeks in April while three offices were assessed using short measurements (5 min spot measurements).

\subsubsection{Simulation}

A building energy model (BEM) of the case study was implemented under TrnSys 17. A representative sample of the campus, with respect to uses and occupation levels, was chosen to 
develop the model. The considered sample is an intermediate level, the $2^{\text {nd }}$ floor, of building \#2 (see Figure 2) for instance. The sample was instrumented with ambient temperature (AT), relative humidity $(\mathrm{RH})$ and Carbon dioxide $\left(\mathrm{CO}_{2}\right)$ sensors in each room. The temperatures and fluids flow rates in the HVAC system were also measured. The measurement campaign lasted four weeks. Occupancy and equipment's heat gain were also taken into account. The BEM was validated according to the experimental data before being used to test various scenarios. The different scenarios as well as their impact on the building energy consumption will be presented in section 4.4 .

\section{Results}

\subsection{Building}

Several parameters of the building envelope, such as the heat loss coefficients (through transmission $\mathrm{H}_{t}$ and through infiltration $\mathrm{H}_{\mathrm{i}}$ ) and the thermal mass are required for the BEM development. Specific measurements were implemented to determine these parameters:

\section{Heat loss through transmission $\mathrm{H}_{\mathrm{t}}$ :}

The building's walls composition was known from the building plans. A first estimation of $\mathrm{H}_{\mathrm{t}}$ was then obtained through calculations. In addition, U-value was determined through simultaneous three temperature measurements at the wall inner surface, one temperature measurement at the wall outer surface and indoor and outdoor temperature measurements. The heat flux is then calculated between the outer surface and the outdoor temperature using a conventional convection/radiation heat exchange coefficient. The flux value is then used to deduce U-value from the temperature gradient through the considered wall. Finally, the calculated values from the plan were used in the simulations. A value of $U=0.38 \mathrm{~W} / \mathrm{m}^{2} . \mathrm{K}$ was obtained for the external wall. The internal walls were not considered since the considered room and the neighbouring are assumed to be at the same uniform temperature.

\section{Thermal mass:}

Once the building heat loss coefficient determined, the building thermal mass was determined by identification to match experimental data of the building temperature variation without internal heat gains. Indeed, the HVAC systems were shut down during three days of zero occupancy to reduce the number of unknown parameters. The collected data during this 
experimental sequence were then used to adjust the BEM parameters in general, and the thermal mass in particular.

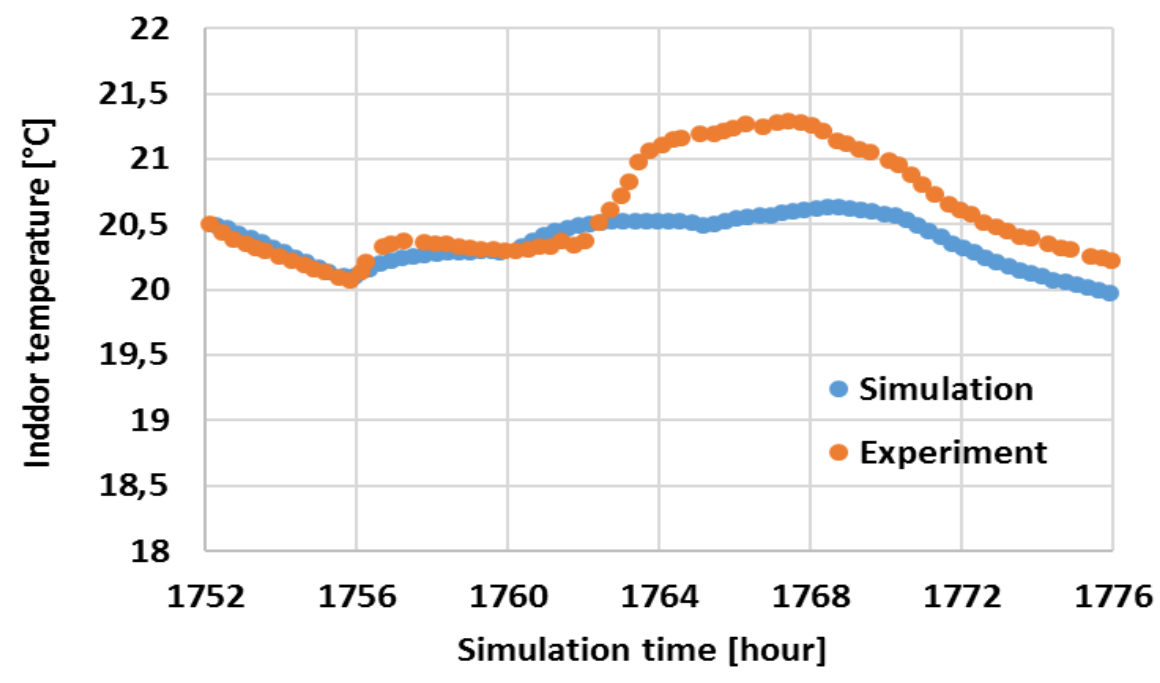

Figure 5 : Experimental and simulated indoor temperature variation during 24 hours

The obtained parameters were used in the BEM to simulate the building thermal behaviour under a set of recommendations. A simulation result obtained during the validation process is presented in Figure 5. We observe a maximal temperature difference of $1^{\circ} \mathrm{C}$. Knowing that the used sensors best accuracy is of $0.5^{\circ} \mathrm{C}$, this discrepancy between simulation and experimental data is not significant. In addition, the larger discrepancies are observed during daytime. These differences are probably due to inappropriate handling of solar radiation in general and diffuse solar radiation in particular. Indeed, the experimental data presented in Figure 5 were measured during a cloudy day with no direct solar radiation. Besides, the solar radiation data used for simulation were measured in a different location a few kilometres from the considered site.

\subsection{Energy supply:}

\section{Annual consumption:}

Electricity, gas and thermal energy consumption are presented in 6. Data presented in Figure 6-a and Figure 6-b are obtained through bills while Figure 6-b shows the thermal energy consumption as deduced from measured fluids flow and temperatures in the distribution system. A significant difference can be observed between figure 6-a and 6-b due to the thermal energy production and distribution system yield.

The overall annual consumptions are of almost $4000 \mathrm{MWh}$ and 5000 for electricity and gas, respectively. 


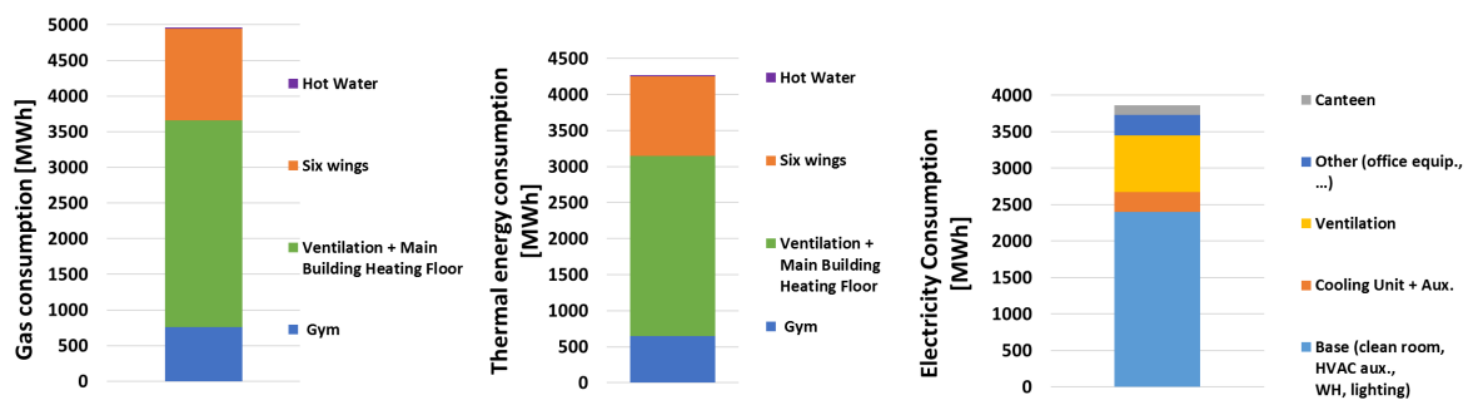

Figure 6 : Annual electricity (a), gas (b) and thermal energy (c) consumption for each energy consumer of the building.

\section{Consumption dynamics:}

Monthly energy consumption including that of gas and electricity are shown in Figure 7. For electricity consumption, monthly bill goes from 145 MWh in Aug-2015 to 429 MWh in Jan- 2015. Compared with neighbouring months, we noticed lower consumption in August, December and February. These are mainly due to vacations with no students and a lower attendance of administrative or faculties staff. Lab related consumptions are then reduced during these periods.

Regarding gas which is mainly used to provide heating (the sanitary hot water service only began on Oct-2014), its consumption varies from 94 MWh in Oct-2014 to 1050 MWh in Feb-2015. This is visibly in accordance with seasonal heating demands and can be explained with the energy signature method.

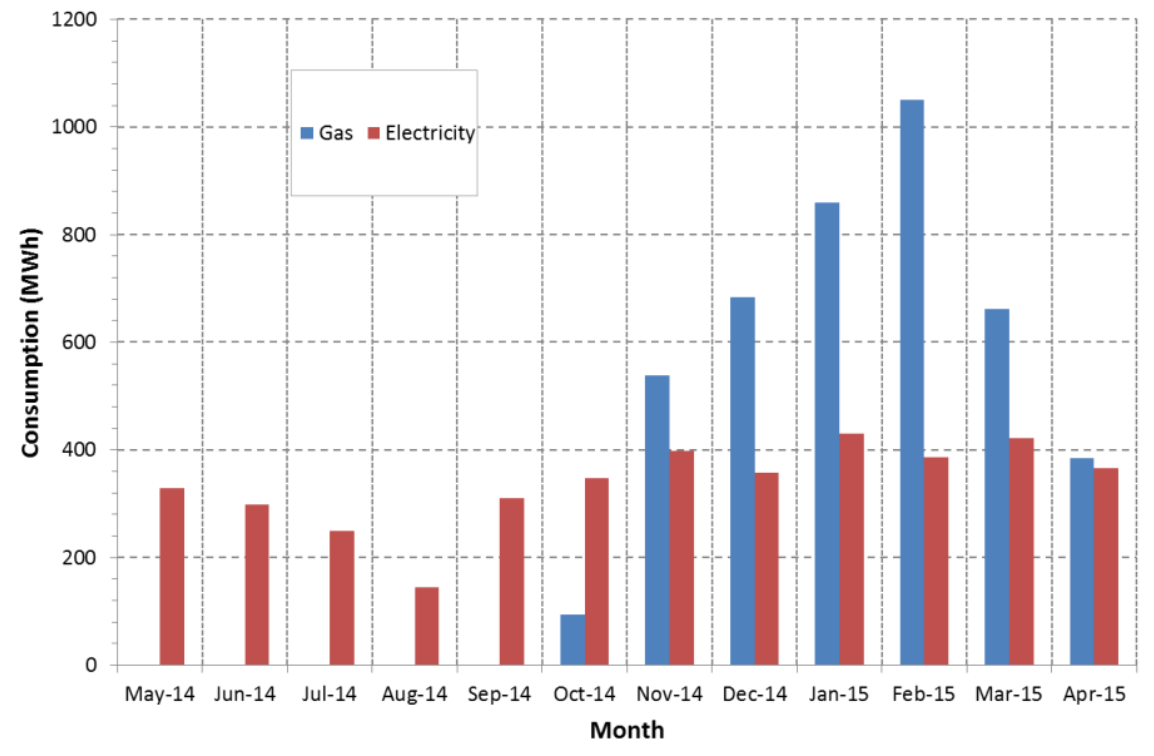

Figure 7 : Total energy consumption from May-2014 to Apr-2015

Larger electricity consumption is observed in winter than that during summer period. Climate related electricity consumption is due to cooling units (providing cooling to data canters and 
clean rooms) as well as auxiliary equipment (pumps, ventilators, etc.). It seems that the heating system auxiliary equipment (heating floor and $\mathrm{AHU}$ ) consumption represents a big part in the total electricity demand. The energy signature method correlating energy consumption to HDD are then used to interpret this phenomenon.

Gas and electricity consumptions during the 7 months of heating (from Oct-2014 to Apr-2015) are shown in Figure 8 in relation with monthly recorded HDD in a meteorological station in Orly, similar to the local climate situation. This correlation shows a clear increase in gas consumption under larger HDD values, i.e., when outdoor temperature is lower. Moreover, the electricity consumption increases also with HDD value, indicating that auxiliary equipment is operated longer.

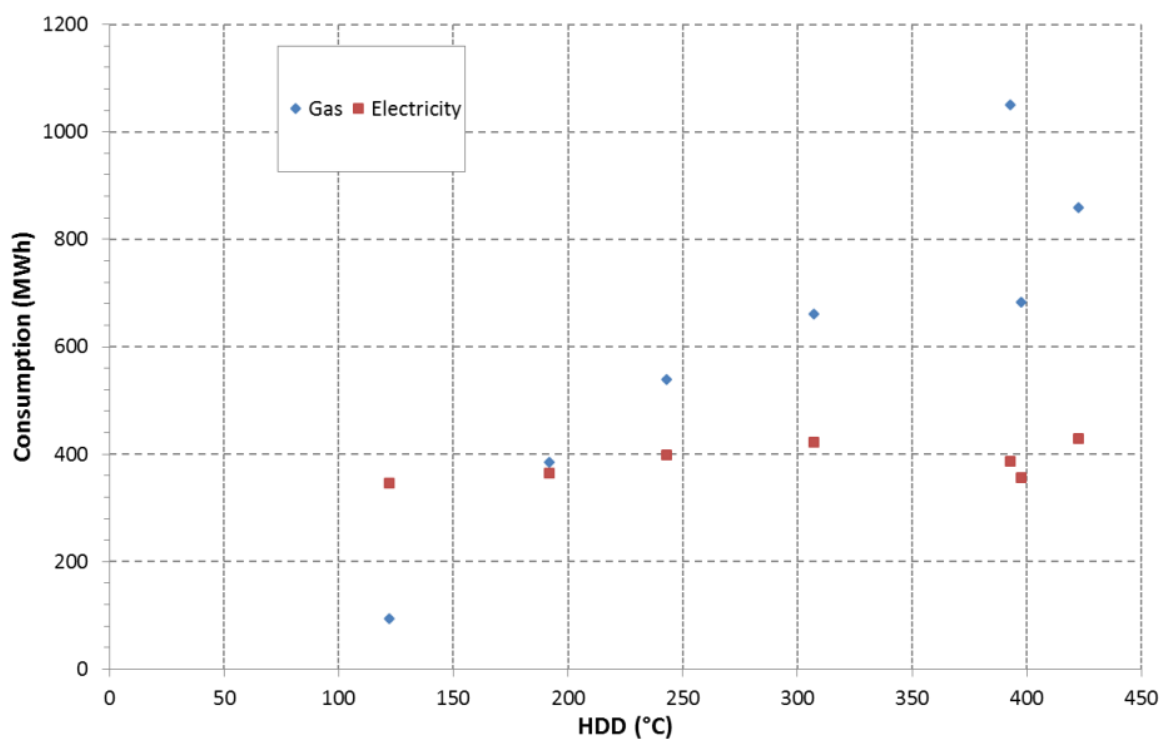

Figure 8. Monthly gas and electricity consumption as a function of the Heating Degree Days (HDD) during heating season from Oct-2014 to Apr-2015

It is worth noting that at a HDD of $398^{\circ} \mathrm{C}$ in Dec 2014 , compared with a HDD of $393^{\circ} \mathrm{C}$ in Feb 2015 , a smaller gas consumption is recorded. This is due to holiday period when the campus is completely closed in December during 1 week. Otherwise, the gas consumption follows a linear curve with HDD.

The variation of energy consumption with HDD during a shorter period is also interesting. Shown in Figure 9 below are daily energy consumption varying with daily HDD values, recorded from Jan-13-2015 to Feb-13-2015. Since the occupation varies between weekdays and weekends, we separated these consumption points. 


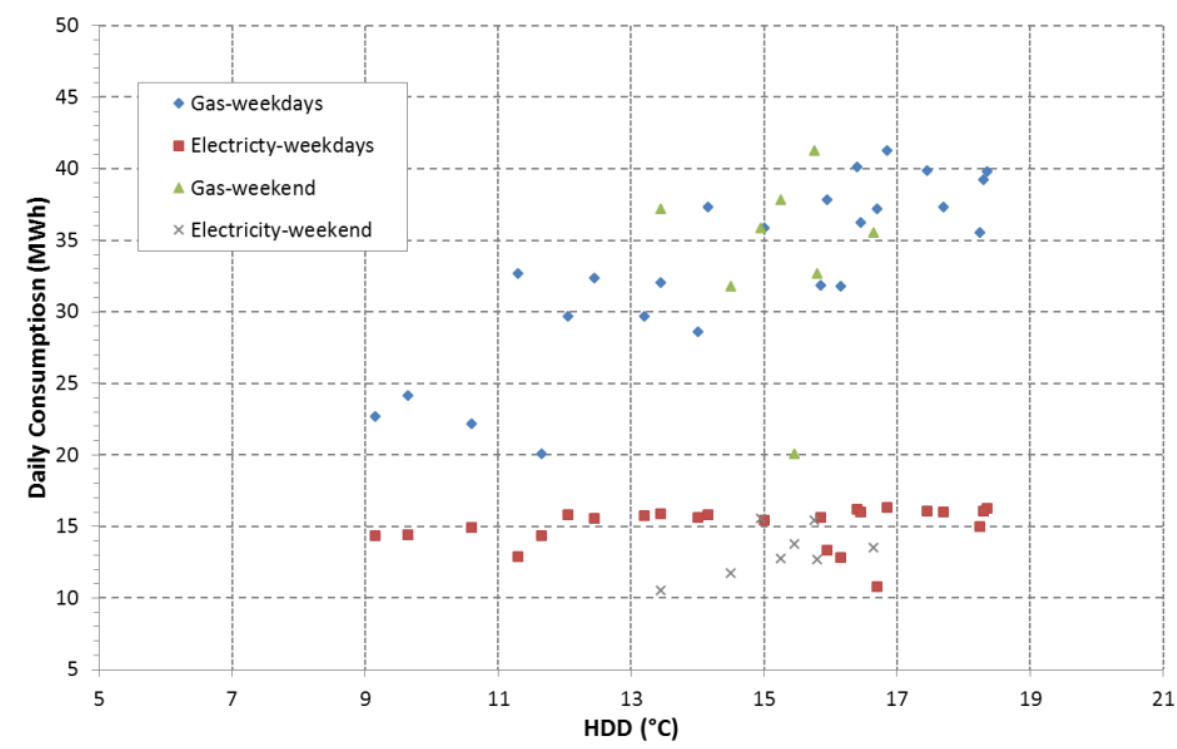

Figure 9.Gas and electricity consumption as a function of the Heating Degree Days (HDD) during heating season from Jan-13-2015 to Feb-13-2015

From the electricity point of view, consumptions during occupation days vary only slightly with $\mathrm{HDD}$. For $\mathrm{HDD}<12{ }^{\circ} \mathrm{C}$, daily electricity consumption is smaller than $15 \mathrm{MWh}$. Otherwise, the daily consumption is generally larger but still within $16.3 \mathrm{MWh}$. During weekends without occupation, however, the dependency of electricity consumption to HDD seems to be more striking. Daily electricity consumptions of $11 \mathrm{MWh}$ and $15 \mathrm{MWh}$ were measured for two different weekends with an $\mathrm{HDD}$ of $13.5^{\circ} \mathrm{C}$ and $17^{\circ} \mathrm{C}$, respectively.

These observations could finally be explained by the operator energy management strategy. Indeed, the air system is sometimes kept working even during weekends to guarantee a comfortable temperature on Monday morning, especially under peak cold situations. However, the air system consumes $8.8 \mathrm{~kW}$ electricity for each of the six buildings in addition to another three AHU for the central hall and the gym. This means that the injection of a reasonable thermal energy in the building through the air system to keep a comfortable environment induces a significant increase of electricity consumption. This strategy can be improved by using the water system as much as possible for the building preheating since there is no need for air renewal outside occupation time slots.

Another diagnostic has been done to the heating floor system. The inlet temperature is controlled by a substation according to measured outdoor temperature. The six substations were instrumented to measure inlet and outdoor temperatures during one week and determine the heating curves used by the substation control system. The obtained results are presented in 
Figure 10 for each of the six buildings \#1 to \#6. They clearly show that, under identical climate conditions, substations are sending water at different temperatures into the six buildings. The sending temperatures for buildings \#1 and \#4 vary from $22{ }^{\circ} \mathrm{C}$ to $33{ }^{\circ} \mathrm{C}$, while those from substations \#1, \#3 and \#5 are at least $5{ }^{\circ} \mathrm{C}$ larger. Considering that these buildings host the same kind of activities, and since occupant of buildings \#1 and \#4 experience an acceptable thermal comfort, buildings \#1, \#3 and \#5 are overheated.

In building \#6, two floors are occupied by clean room facilities. They have been addressed separately. The heating behaviour shown in Figure 10 is rather stable since the sending water temperature varies from $27^{\circ} \mathrm{C}$ to $32^{\circ} \mathrm{C}$.

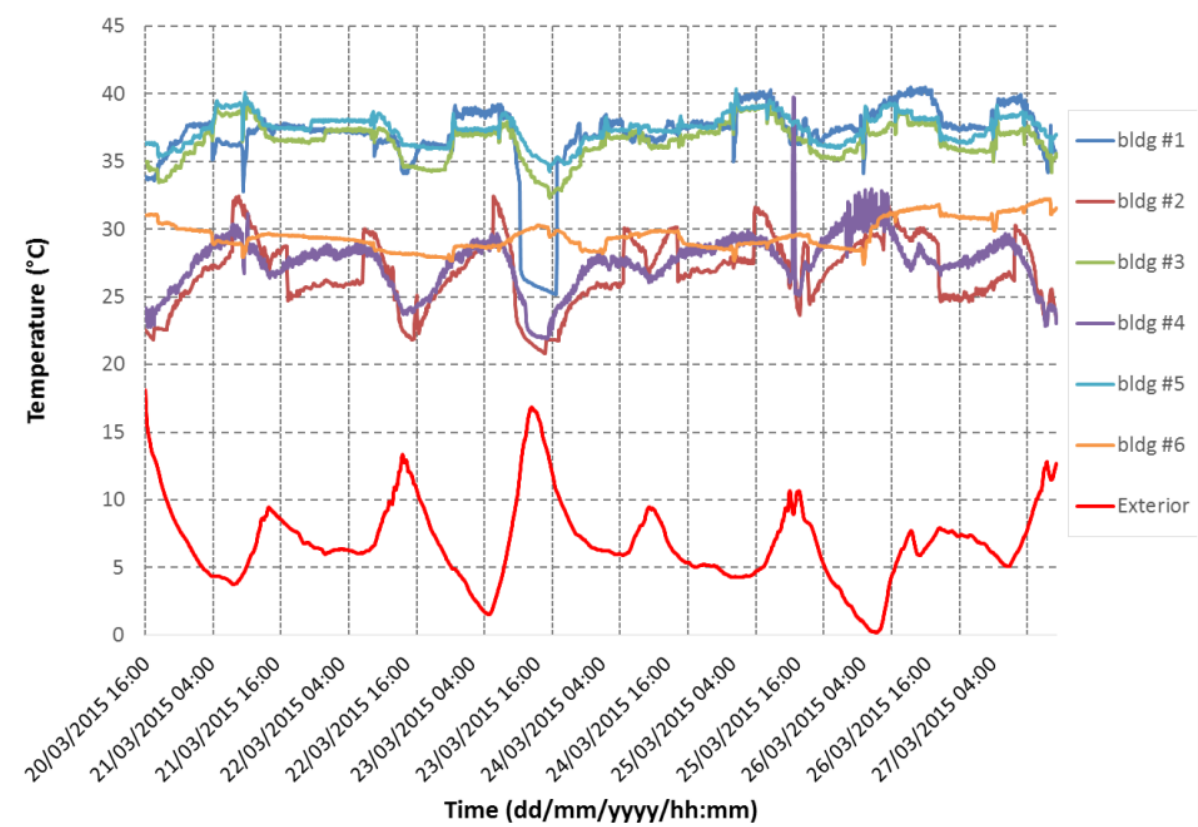

Figure 10. Comparison of identified heating curves between original and renovated substations

In addition to the previously mentioned discrepancies between the different substations, it is worth noting that a night mode heating curve is implemented in substation \#2, contrarily to the five others. Each day from 19:00 to 8:00 next morning, water with lower temperature is circulated into the heating floor system. This way, energy savings are obtained since a decrease in the ambient temperature during non-occupancy periods does not affect the thermal comfort. By correlating outdoor and sending temperatures, we obtained the heating curves of each building, as shown in Figure 11 as well as in Table 2 . These curves clearly show abnormal heating control of building \#6, and overheating in buildings \#1, \#3 and \#5. 


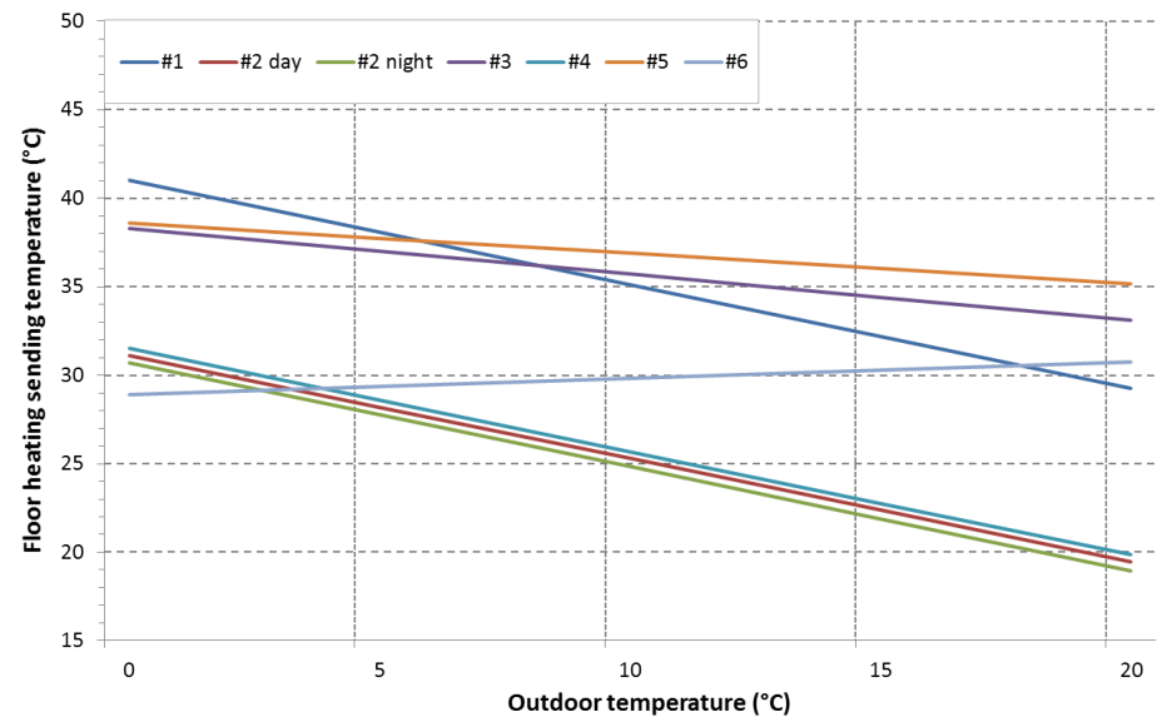

Figure 11. Heating curves of different substations. The substation heating floor equipment of building \#2 and \#4 where replaced in 2012 contrary to the four others.

Table 2. Identified heating curves of different substations

\begin{tabular}{|c|c|c|c|}
\hline \multirow[t]{2}{*}{ Identifications } & \multirow[t]{2}{*}{ Buildings } & \multicolumn{2}{|c|}{$\begin{array}{l}\text { Heating curve parameters } \\
\qquad \mathrm{T}_{\text {water }}=\mathrm{a} \mathrm{T}_{\text {ext }}+\mathrm{b}\end{array}$} \\
\hline & & $a$ & b \\
\hline \multirow{3}{*}{ Normal and economic regulations } & $\# 4$ & -0.5822 & 31.5 \\
\hline & \#2 day & -0.5816 & 31.1 \\
\hline & \#2 night & -0.5875 & 30.7 \\
\hline \multirow{3}{*}{ Overheated and energy consuming regulations } & $\# 1$ & -0.5878 & 41.0 \\
\hline & $\# 3$ & -0.2597 & 38.3 \\
\hline & $\# 5$ & -0.1722 & 38.6 \\
\hline Abnormal heating regulation & \#6 & 0.0928 & 28.9 \\
\hline
\end{tabular}

As a result, retrofitting recommendations can be made to the renovation of substations $\# 1$, \#3, \#5 and \#6 so that different heating curves can be adopted, with day and night modes, eventually. The experimental campaign on ventilation performances was carried out during summer through two sessions: from July $20^{\text {th }}$ to July $23^{\text {rd }} 2015$ and from August $28^{\text {th }}$ to September $3^{\text {rd }}$ 2015 , respectively.

Table 3 summarizes the average values of outdoor parameters (air temperature, wind velocity and relative humidity) for the two sessions. The recorded values correspond to the local summer climate (consistent with trends of recent years). The outdoor air temperature varied between $14^{\circ} \mathrm{C}$ and $29^{\circ} \mathrm{C}$ (including night periods) with an average around $20^{\circ} \mathrm{C}$ while the relative humidity 
varied between $42 \%$ and $72 \%$. Furthermore, values of wind speed ranging between $0.1 \mathrm{~m} / \mathrm{s}$ and $2.30 \mathrm{~m} / \mathrm{s}$ were recorded during the two sessions with an average of $1.03 \mathrm{~m} / \mathrm{s}$ for the whole period. Finally, the analysis of the outdoor climate parameters revealed some differences between the four ventilation strategies, especially for the air temperature which oscillate from $0.5^{\circ} \mathrm{C}$ and $2.5^{\circ} \mathrm{C}$ during the measurement period corresponding to each strategy.

The indoor climate was relatively moderate and within the comfort range fixed by the standards with an average operative temperature around $23^{\circ} \mathrm{C}$ (corresponding to class I according to the EN15251) and an average relative humidity around 50\%. On the other hand, significant differences were found between the strategies $\left(2^{\circ} \mathrm{C}\right.$ on average). In fact, the temperature differences between indoor and outdoor were on average around $4^{\circ} \mathrm{C}(+/-1.71)$.

Table 3.summary of the weather data during the assessment campaign (average on the four ventilation strategies)

\begin{tabular}{|l|c|c|c|}
\hline $\begin{array}{l}\text { Parameter/session } \\
\text { Symbol }\end{array}$ & $\begin{array}{c}\text { Air temperature } \\
\left.\text { Tout }^{\circ}{ }^{\circ} \mathrm{C}\right]\end{array}$ & $\begin{array}{c}\text { Relative humidity } \\
\text { RHout }[\%]\end{array}$ & $\begin{array}{c}\text { Wind speed } \\
\mathbf{W}_{\mathbf{s}}[\mathrm{m} / \mathrm{s}]\end{array}$ \\
\hline Mean & 19.17 & 60.16 & 1.03 \\
Min & 14.25 & 42.05 & 0.45 \\
Max & 25.05 & 77.25 & 1.90 \\
\hline
\end{tabular}

To obtain an order of magnitude of the effect of airtightness on the ventilation, a tracer gas decay method was adopted to estimate infiltrations trough envelop. The technique differs from the one adopted to estimate the AEH only in one aspect: after injection of the tracer gas, the ventilation system was totally deactivated. Thereby, the AEH corresponding to infiltration trough the envelope was $0.029 \mathrm{~h}^{-1}$, which corresponds to an air flow rate of $1,46 \mathrm{~m}^{3} / \mathrm{h}$.

The measured air flow rates for the different ventilation strategies were between $54 \mathrm{~m}^{3} / \mathrm{h}$ and $183 \mathrm{~m}^{3} / \mathrm{h}$ (Table 4). In the mechanical ventilation scenario $\left(V_{M}\right)$, the air flow rates were estimated between 43.9 and $54 \mathrm{~m}^{3} / \mathrm{h}$. These results are within the labour code for educational buildings $\left(25 \mathrm{~m}^{3} / \mathrm{h}\right.$ ) but are quite small according to the EN 15251. In fact, the EN 15251 recommends 59.4 $\mathrm{m}^{3} / \mathrm{h}$ for existing buildings and $102.6 \mathrm{~m}^{3} / \mathrm{h}$ for new and refurbished buildings. It should be noted that the mechanical strategy is the worst performing in terms of ventilation rates. In fact, the single side ventilation with one window $\left(V_{\mathrm{N} 1}\right)$ presented air flow rates between $56 \mathrm{~m}^{3} / \mathrm{h}$ and 75 $\mathrm{m}^{3} / \mathrm{h}$ while $V_{\mathrm{N} 2}$ flow rate values ranged between $127 \mathrm{~m}^{3} / \mathrm{h}$ and $166 \mathrm{~m}^{3} / \mathrm{h}$. Finally, the mixed mode ventilation flow rates ranged between $58 \mathrm{~m}^{3} / \mathrm{h}$ and $110 \mathrm{~m}^{3} / \mathrm{h}$. 
The air flow rates measured by tracer gas techniques are below those measured on the supply vent $\left(66.7 \mathrm{~m}^{3} / \mathrm{h}\right)$. This gap can be explained by two factors. First, the air flow rate measured on the supply vent does not correspond to the whole air flow. It does not consider the air flow through the envelope and some dead spaces as the technical space under the ceiling. Second, it does not exactly match with the parameter measured by tracer gas since it addresses only the local mechanical supply. In addition, the estimation made by tracer gas is much more accurate than a simple hot wire anemometer $(0.1 \mathrm{~m} / \mathrm{s}$ accuracy) coupled with a cone. Finally, we observed significant gaps between the values reported on the building plans $\left(109 \mathrm{~m}^{3} / \mathrm{h}\right)$ and the measured ones.

Table 4.results of the measured $A C R$ and air flow rates for each strategy using the effective volume $\left(Q_{1}\right)$ and the geometrical volume $\left(Q_{2}\right)$

\begin{tabular}{|c|c|c|c|}
\hline & Test 1 & Test 2 & Test 3 \\
\hline \multicolumn{4}{|c|}{ Mechanical ventilation $\left(\mathrm{V}_{\mathrm{M}}\right)$} \\
\hline ACR $[1 / h]$ & 1.10 & 0.89 & 0.90 \\
\hline Airflow rate $Q_{1}\left[m^{3} / h\right]$ & 54.13 & 43.93 & 44.16 \\
\hline Airflow rate $Q_{2}\left[m^{3} / h\right]$ & 59.80 & 48.54 & 48.79 \\
\hline Local supply airflow rate $\left[\mathrm{m}^{3} / \mathrm{h}\right]$ & 66.7 & 65.02 & 63.01 \\
\hline \multicolumn{4}{|c|}{ Natural ventilation with one window $\left(\mathrm{V}_{\mathrm{N} 1}\right)$} \\
\hline ACR [1/h] & 1.51 & 2.00 & 1.14 \\
\hline Airflow rate $Q_{1}\left[m^{3} / h\right]$ & 74.43 & 98.10 & 56.07 \\
\hline Airflow rate $Q_{2}\left[m^{3} / h\right]$ & 82.24 & 108.39 & 61.95 \\
\hline Local supply airflow rate $\left[\mathrm{m}^{3} / \mathrm{h}\right]$ & 0 & 0 & 0 \\
\hline \multicolumn{4}{|c|}{ Natural ventilation with three windows $\left(\mathrm{V}_{\mathrm{N} 2}\right)$} \\
\hline ACR $[1 / h]$ & 2.60 & 3.39 & No test \\
\hline Airflow rate $Q_{1}\left[m^{3} / h\right]$ & 127.84 & 166.34 & \\
\hline Airflow rate $Q_{2}\left[m^{3} / h\right]$ & 141.25 & 183.78 & \\
\hline Local supply airflow rate $\left[\mathrm{m}^{3} / \mathrm{h}\right]$ & 0 & 0 & \\
\hline \multicolumn{4}{|c|}{ Mixed mode ventilation $\left(\mathrm{V}_{\mathrm{MM}}\right)$} \\
\hline ACR $[1 / h]$ & 1.45 & 2.25 & 1.18 \\
\hline Airflow rate $Q_{1}\left[m^{3} / h\right]$ & 71.35 & 110.27 & 57.81 \\
\hline Airflow rate $\mathrm{Q}_{2}\left[\mathrm{~m}^{3} / \mathrm{h}\right]$ & 78.83 & 121.84 & 63.87 \\
\hline Local supply airflow rate $\left[\mathrm{m}^{3} / \mathrm{h}\right]$ & 54.12 & 53.52 & 55.13 \\
\hline
\end{tabular}


Table 5 presents the result of the analysis on the ventilation effectiveness on the basis of age of the air measurements and air exchange efficiency.

The age of the air varies between $0.18 \mathrm{~h}$ and $0.7 \mathrm{~h}$ depending on the ventilation strategy. During the mechanical ventilation strategy, the mean age of the air was estimated around $0.7 \mathrm{~h}$ in the breathing zone while the natural ventilation strategies $V_{\mathrm{N} 1}$ and $V_{\mathrm{N} 2}$ presents respectively $0.46 \mathrm{~h}$ and $0.16 \mathrm{~h}$. The age of the air in the breathing zone for the mixed mode ventilation was around $0.18 \mathrm{~h}$. As expected, we notice that the magnitude of those results correspond to the results in terms of air flow rate for each strategy.

The analysis of the air exchange efficiency for each strategy revealed some heterogeneities with values between $37 \%$ and $63 \%$. The mechanical ventilation is the closest to the mixing ventilation (around 50\%). The strategies $\mathrm{V}_{\mathrm{N} 2}$ and $\mathrm{V}_{\mathrm{MM}}$ present dead zones (zones without fresh air) with $37.67 \%$ and $39.50 \%$ respectively. It means than the air is not totally mixed and a part of the fresh air is extracted with the old air. The strategy $V_{N_{1}}$ corresponds to a piston flow with $63 \%$ which means that there are few dead zones.

Table 5.Measurement results and the analysis of the ventilation effectiveness for each strategy

\begin{tabular}{|c|c|c|c|}
\hline & Breathing zone & Zone 2 & Zone 3 \\
\hline \multicolumn{4}{|c|}{ Mechanical ventilation $\left(\mathrm{V}_{\mathrm{M}}\right)$} \\
\hline Age of the air [h] & 0.70 & 0.68 & 0.71 \\
\hline Air exchange efficiency [\%] & 52.33 & 52.15 & 54.94 \\
\hline \multicolumn{4}{|c|}{ Natural ventilation with one window $\left(\mathrm{V}_{\mathrm{N} 1}\right)$} \\
\hline Age of the air [h] & 0.46 & 0.47 & 0.47 \\
\hline Air exchange efficiency [\%] & 63.10 & 64.13 & 64.39 \\
\hline \multicolumn{4}{|c|}{ Natural ventilation with three windows $\left(\mathrm{V}_{\mathrm{N} 2}\right)$} \\
\hline Age of the air [h] & 0.16 & 0.15 & 0.16 \\
\hline Air exchange efficiency [\%] & 37.67 & 34.13 & 37.27 \\
\hline \multicolumn{4}{|c|}{ Mixed mode ventilation ( $\left.\mathrm{V}_{\mathrm{MM}}\right)$} \\
\hline Age of the air [h] & 0.18 & 0.19 & 0.18 \\
\hline Air exchange efficiency [\%] & 39.50 & 37.62 & 34.84 \\
\hline
\end{tabular}

The assessment of the ventilation performances through different strategies allows us to conclude on the behaviour of the most realistic ventilation strategies and to check the operating conditions of the AHU and their impact on a representative office. The mechanical ventilation analysis shows a concordance with the values fixed by the labour code. However, the recorded 
values were inconsistent with those indicated on the plans or those that could be measured in the ducts and vents. In fact, it is important to notice the differences between the values fixed at the design stage and the real ones. In addition, this campaign allows us to rank the ventilation system according to the European standard (EN 15251).

In addition to the mechanical ventilation assessment, we tested some alternative solutions to improve the ventilation performances while satisfying the energy constraints. In fact, the natural and mixed mode strategies showed good results in terms of air change rates. However, it is worth reminding that the present experimental campaign concerns an individual office. Its generalization should be done carefully when we consider classrooms which are characterised by a much larger occupancy density and can exhibit poor indoor air quality and thermal discomfort in some cases.

Furthermore, the measurements of ventilation effectiveness proved that the ventilation with large flow rates is not necessarily the most efficient in the way to provide and distribute fresh air, particularly in the breathing zone. In the present study, the strategies $V_{\mathrm{N} 2}$ and $\mathrm{V}_{\mathrm{MM}}$ are the fastest in providing fresh air to the breathing zone. On the contrary, the mechanical ventilation is clearly inappropriate especially in rooms with high occupancy density. Finally, the single side natural ventilation is a good alternative because it provides fresh air quickly and presents relatively few dead zones.

Obviously, the natural and mixed mode strategies show good performances in terms of indoor air quality, which is the main concern of ventilation systems. However, they also need to be assessed during the heating season to evaluate their impact on thermal comfort and energy efficiency.

\subsection{Thermal comfort and indoor air quality}

Concerning thermal comfort, three surveys were carried out in different periods to follow the season's outdoor conditions (Table 6) and to allow the establishment of different evaluation methodologies. The adopted methodologies simultaneously address the comfort and the analysis of practices. This will help in providing a comprehensive view of internal building conditions and user behaviour. 
Table 6. Details of the three surveys

\begin{tabular}{|c|c|c|c|c|c|c|c|}
\hline $\begin{array}{c}\text { N. } \\
\text { survey }\end{array}$ & Period & $\begin{array}{c}\text { N. of } \\
\text { offices }\end{array}$ & $\begin{array}{c}\text { N. of } \\
\text { offices' } \\
\text { occupants }\end{array}$ & $\begin{array}{c}\text { Offices } \\
\text { localisation }\end{array}$ & $\begin{array}{c}\text { N. of } \\
\text { classrooms }\end{array}$ & $\begin{array}{c}\text { N. of } \\
\text { classrooms' } \\
\text { occupants }\end{array}$ & $\begin{array}{c}\text { Classrooms } \\
\text { localisation }\end{array}$ \\
\hline $\mathbf{1}$ & $\begin{array}{c}\text { February } \\
2015\end{array}$ & 45 & 51 & $\begin{array}{c}\text { All buildings, all } \\
\text { floors except } \\
\text { ground floor }\end{array}$ & 4 & 165 & $\begin{array}{c}\text { Buildings } 1,2, \\
3 ; 2^{\text {nd }}, 3^{\text {rd }}, \\
\text { and } 4^{\text {th }} \text { floor }\end{array}$ \\
\hline $\mathbf{2}$ & $\begin{array}{c}7-16 \text { April } \\
2015\end{array}$ & 71 & 75 & $\begin{array}{c}\text { All buildings, all } \\
\text { floors except } \\
\text { ground floor }\end{array}$ & 3 & 287 & $\begin{array}{c}\text { Buildings } 1,3 ; \\
2^{\text {nd }} \text { and } 4^{\text {th }} \\
\text { floor }\end{array}$ \\
\hline $\mathbf{3}$ & $\begin{array}{c}1-14 \text { July } \\
2015\end{array}$ & 8 & 69 & $\begin{array}{c}\text { Building 3, all } \\
\text { floors except } \\
\text { ground floor }\end{array}$ & - & - & - \\
\hline
\end{tabular}

In particular the target sets for each survey are:

- February and April Survey: a) evaluation of comfort and user behaviour through questionnaires provided during the period of occupation and physical measurements; b) comparison between the obtained results and the standards / literature.

- July survey: a) evaluation of comfort and user behaviour as previously mentioned; b) evaluation of the building comfort category according to the EN 15251 standard.

Table 7.recorded values of $T_{g}, T_{a}, T_{m r}, V_{a}$, HR for offices and classrooms during the two firsts surveys. For offices, $V_{a}$ is not a recorded but hypothesized value.

\begin{tabular}{|l|l|l|l|l|l|l|l|}
\hline Period & Place & Value & $\mathbf{T}_{\mathbf{g}}\left({ }^{\circ} \mathbf{C}\right)$ & $\mathbf{T}_{\mathbf{a}}\left({ }^{\circ} \mathbf{C}\right)$ & $\mathbf{T}_{\mathbf{m r}}\left({ }^{\circ} \mathbf{C}\right)$ & $\left.\mathbf{V}_{\mathbf{a}} \mathbf{( m} / \mathbf{s}\right)$ & $\mathbf{R H}(\mathbf{\%})$ \\
\hline FEBRUARY 2015 & CLASSROOMS & $\operatorname{mean}$ & 23.13 & 23.32 & 23.05 & 0.01 & 30.91 \\
\hline & & $\max$ & 26.25 & 26.62 & 26.62 & 0.08 & 45.45 \\
\hline & & $\min$ & 18.76 & 19.60 & 17.89 & 0.00 & 23.37 \\
\hline & & $\mathrm{SD}$ & 1.48 & 1.57 & 1.64 & 0.01 & 5.44 \\
\hline & OFFICES & $\operatorname{mean}$ & 23.49 & 23.40 & 23.57 & 0.10 & 26.52 \\
\hline & & $\max$ & 27.00 & 26.77 & 27.39 & 0.10 & 34.50 \\
\hline & & $\min$ & 19.84 & 19.87 & 19.81 & 0.10 & 22.00 \\
\hline & & SD & 1.55 & 1.37 & 1.74 & 0.10 & 2.40 \\
\hline & CLASSROOMS & mean & 24.01 & 23.93 & 24.07 & 0.15 & 34.65 \\
\hline & & $\max$ & 28.44 & 28.18 & 28.62 & 0.15 & 50.57 \\
\hline & & $\min$ & 19.89 & 19.68 & 19.66 & 0.15 & 21.60 \\
\hline & & SD & 1.87 & 1.84 & 1.90 & 0.15 & 6.91 \\
\hline & OFFICES & $\operatorname{mean}$ & 22.84 & 23.19 & 22.49 & 0.10 & 26.29 \\
\hline & & $\max$ & 25.84 & 25.63 & 26.05 & 0.10 & 30.40 \\
\hline & & $\min$ & 18.81 & 19.30 & 17.11 & 0.10 & 22.67 \\
\hline & & SD & 1.53 & 1.39 & 1.82 & 0.10 & 2.05 \\
\hline
\end{tabular}

During the two first surveys, both offices and classrooms were investigated for a total of 126 offices' occupants and 452 classrooms' occupants. The used instruments were: a) Indoor climatic station (LSI Lastem) for the air temperature measurement $\left(T_{a}\right)$, mean radiant temperature $\left(T_{m r}\right)$, the air velocity $\left(\mathrm{V}_{\mathrm{a}}\right)$ and the relative humidity $(\mathrm{RH})$; b) Multifunctional device for spot measurements of the air temperature $\left(T_{a}\right)$, the mean radiant temperature $\left(T_{m r}\right)$, the air velocity 
$\left(\mathrm{V}_{\mathrm{a}}\right)$, relative humidity $(\mathrm{HR})$ and the $\mathrm{CO}_{2}$ concentration ; $\mathrm{c}$ ) data loggers for the measurement of the air temperature $\left(T_{a}\right)$ of the relative humidity $(\mathrm{RH})$ and the $\mathrm{CO}_{2}$ concentration. Table 7 synthetically reports the recorded values. Instruments a), b) and c) were used in classrooms, while d) were used in offices being easier to move from one room to another. The characteristics of the main sensors are summarized in table 1.

After the measurement campaigns, we calculated the thermal comfort indices PMV (Predicted Mean Vote) and PPD (Predicted Percentage of Dissatisfied) $[55,57]$ for February and April. We used PMV and PPD to evaluate thermal comfort according the EN 15251 standard, which identifies comfort categories for different building typologies. Our case-study building belongs to the category III (existing building); thus the PPD must be lower than $15 \%$ and PMV must be between -0.7 and +0.7 . Figure 12 shows the results for offices (a) and for classrooms (b) in February, highlighting a relative overheating, especially for classrooms.

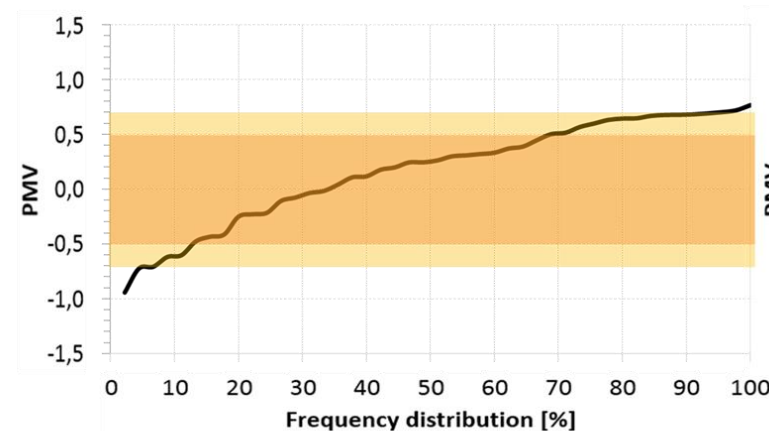

(a)

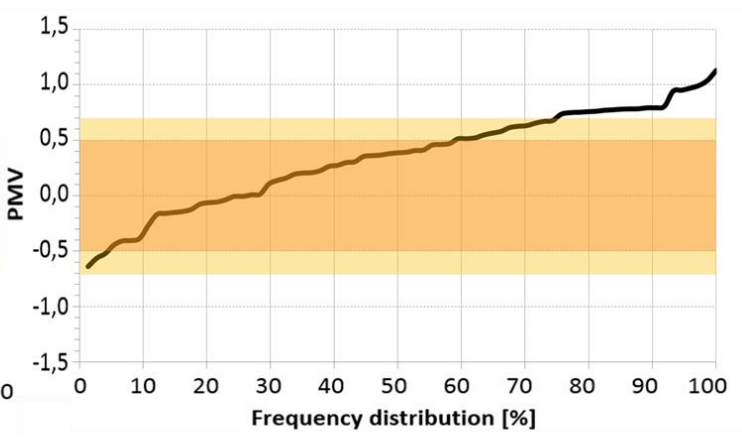

(b)

Figure 12.distribution of PMV for offices (a) and for classrooms (b). The darkest color represents, according to EN 15251, the comfort range of PMV for buildings belonging to category II; the brightest color the range for buildings in category III.

We also compared the correlation between $\mathrm{T}_{\mathrm{op}}$ and PMV with the one between $\mathrm{T}_{\mathrm{op}}$ and TSV (thermal sensation votes, votes expressed by occupants through the questionnaires) and $\mathrm{T}_{\text {op }}$ and TP (thermal preference, votes expressed by occupants). Figure 13 shows the results for offices (a) and classrooms (b) in February. It can be noticed that the neutral temperatures calculated from TSV $\left(21.7^{\circ} \mathrm{C}\right.$ for $\mathrm{a}$ and $\left.\mathrm{b}\right)$ are lower than the ones calculate with $\mathrm{PMV}\left(22.9^{\circ} \mathrm{C}\right.$ for a and $22.5^{\circ} \mathrm{C}$ for b). 


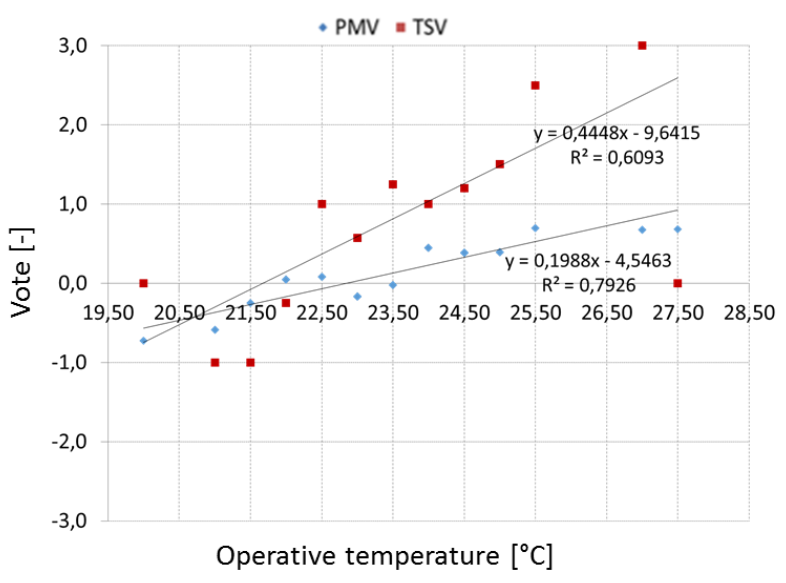

(a)

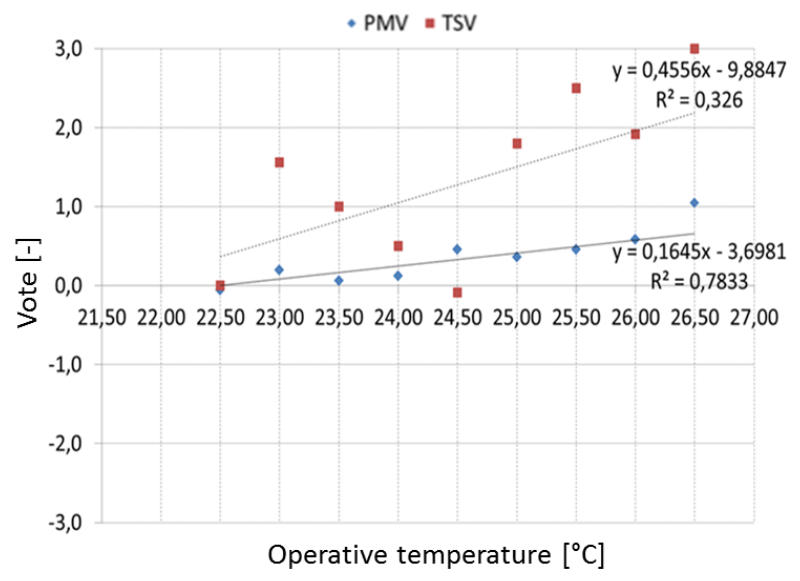

(b)

Figure 13. Correlation between $T_{o p}$ and PMV, Top and TSV for offices (a) and classrooms (b)

The third survey was carried out in July in natural ventilation conditions. The evaluation of comfort was based on the adaptive approach as for the EN 15251 and compared with TSV (thermal sensation vote) and TPV (thermal preference vote) (Figure 14).

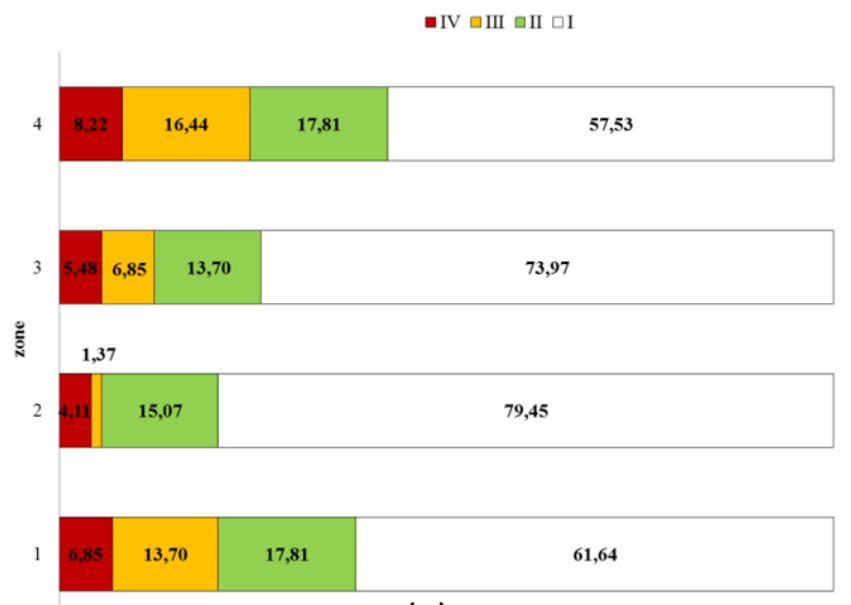

(a)

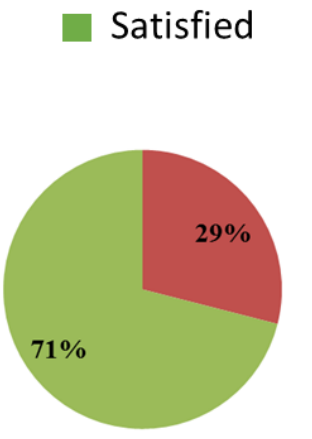

(b)
- Dissatisfied

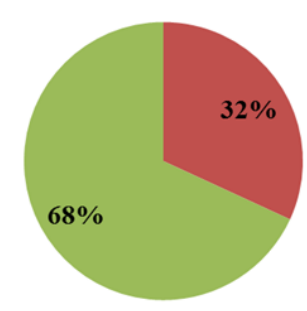

(c)

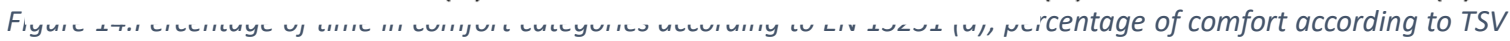
(where the comfort range is $[-1 ; 1])(b)$; and TPV (where the comfort is [0]) (c).

Concerning energy consuming behaviour, results show that occupants fairly frequently recurred to regulation behaviour. Without going into details, we present here in table 8 the results for "open window", "open windows and doors" and "use an additional space heater" for offices during February and April surveys. 
Table 8.Percentages of regulation behaviour for offices during February and April.

\begin{tabular}{|l|l|l|l|l|}
\hline & \multicolumn{2}{|c|}{ February (\%) } & \multicolumn{2}{c|}{ April (\%) } \\
\hline & Quite often & Very often & Quite often & Very often \\
\hline Open windows & 33 & 65 & 43 & 45 \\
\hline Open windows and doors & 24 & 24 & 41 & 29 \\
\hline Use an additional heater & 10 & 33 & 21 & 11 \\
\hline
\end{tabular}

As expected, the IAQ was clearly poor in classrooms. In fact, while the recorded $\mathrm{CO}_{2}$ values in the offices were around 500 ppm above outdoor, the results for the classrooms showed larger values both for average values and peak values during the occupancy. If we consider the ranking proposed in the EN 15251, 86\% of the recorded values during the occupancy were above the 800 ppm (above outdoor) fixed by the standard for the category IV. The average concentration was around 1278 ppm when some peak values were recorded around 2400 ppm (above outdoor).

The main results of the comfort study can be summarized as follows: a) the building has significant thermal discomfort during the three evaluated seasons (winter, spring, summer); b) the concentration of $\mathrm{CO}_{2}$ in classrooms indicates insufficient airflow renew; c) there is a significant presence of energy consuming behaviour such as opening windows and using additional space heaters during the heating season.

The general situation of discomfort identified by comfort indices is confirmed by the analysis of users' behaviour showing a multitude of practices to improve the indoor environmental conditions. Using additional space heaters and opening windows are the most immediate means for adjusting the internal conditions. They can also be classified as energy intensive behaviour. For instance, an additional space heater can increase the energy consumption of an office by $4500 \mathrm{kWh} / \mathrm{month}$.

\subsection{Simulation}

The developed BEM described in section 3.4.4 was used to test several scenarios implementing different improvements of the building envelope and / or the HVAC system. The model is used to quantify the impact of each scenario on the building energy consumption and energy cost compared to the current configuration. The scenarios and results presented in the following paragraphs are obtained under the constraint of an indoor temperature of $20^{\circ} \mathrm{C}$. 
The considered scenarios are: (1) the use of a heating curve lower than the current one; (2) the optimization of the ventilation system scheduling such as its overall functioning duration is reduced while the set point temperature is always reached at 8 A.M; $(3)$ the implementation of a control system on the heating floor which takes into account the indoor temperature as a feedback to reach the set point temperature; (4) In addition to a lower heating curve, an additional insulation of the envelope (a seven-mm thick stone wool layer) is considered; (5) a control system of the heating floor combined with a lower heating curve.

The thermal energy consumption and cost of the building \#2 for each scenario as well as for the original situation are presented in Figure 15 according to an increasing implementation difficulty scale from left to right.

Table 9.relative energy consumption decrease induced by the considered scenarios.

\begin{tabular}{|l|l|}
\hline Scenario & Relative energy consumption reduction \\
\hline $\mathbf{1}$ & $6 \%$ \\
\hline $\mathbf{2}$ & $1 \%$ \\
\hline $\mathbf{3}$ & $14 \%$ \\
\hline $\mathbf{5}$ & $16 \%$ \\
\hline
\end{tabular}

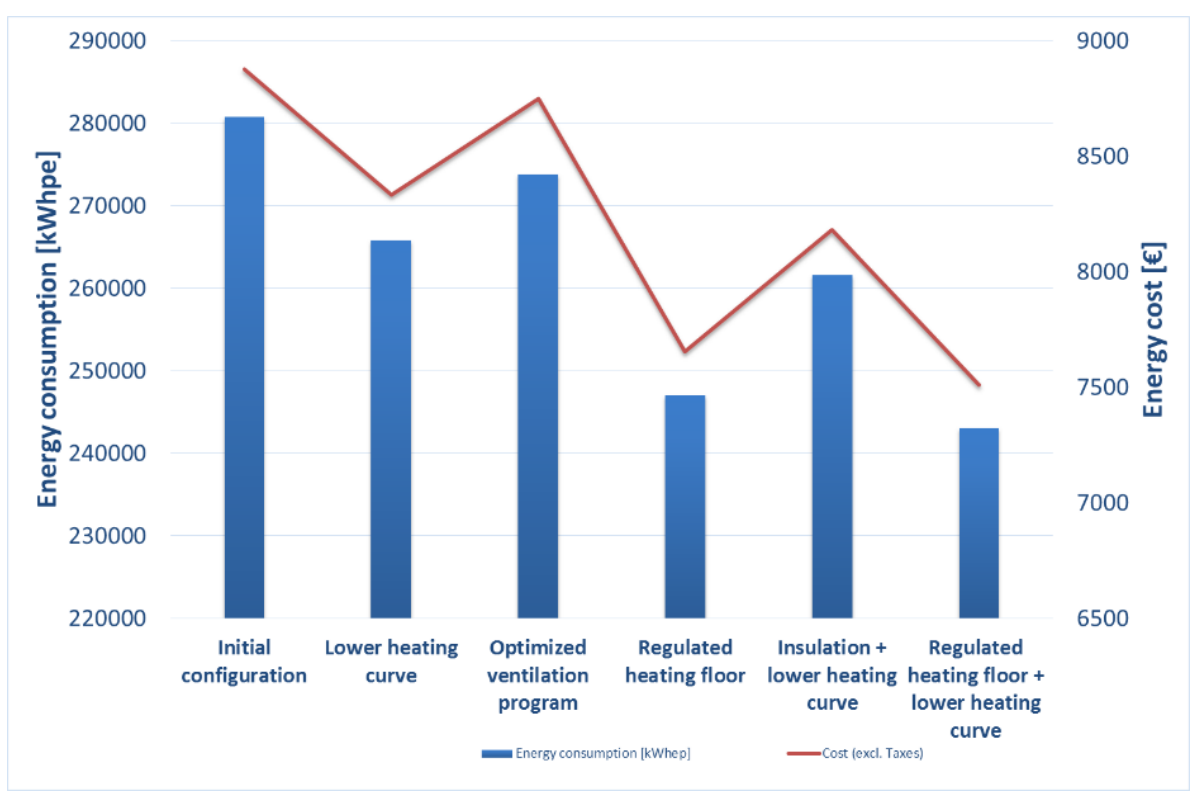

Figure 15. Thermal energy consumption and energy cost of the building \#2 for different scenarios.

The energy consumption savings induced by the different scenarios are reported in Table 9. It can be observed that a significant reduction in consumption, up to $16 \%$, can be obtained by combining a room temperature control system applied to the heating floor and the downscaling of the heating curve. 
Considered independently, the room temperature control system and the heating curve downscaling result in energy consumption reduction of $14 \%$ and $6 \%$, respectively. Consequently, their impacts do not sum up when combined.

On the other hand, an optimization of the scheduling of the ventilation system does not lead to significant energy savings. Indeed, the constraint of reaching the set point temperature at 8 A.M. limits the scheduling possibilities.

It is worth noting that a near zero-cost scenario such as scenario 1 can lead to savings as large as $6 \%$ of the thermal energy consumption.

\section{Discussion}

Throughout the detailed audit, combining analyses on thermal comfort, energy system and ventilation performance, the case study helps giving reliable retrofitting recommendations. The aims of these recommendations are to i) reduce energy consumptions and ii) improve comfort level.

The studied campus has an average consumption of $140 \mathrm{kWh} /\left(\mathrm{m}^{2} \cdot \mathrm{yr}\right)$ of gas and $132 \mathrm{kWh} /\left(\mathrm{m}^{2} \cdot \mathrm{yr}\right)$ of electricity during the period from May 2014 to Apr. 2015. This results in an annual consumption of $480 \mathrm{kWh} /\left(\mathrm{m}^{2} . \mathrm{yr}\right)$ of primary energy. Compared with the study done by Mairie de Paris [16] on primary schools which consume in average $225 \mathrm{kWh} /\left(\mathrm{m}^{2} . \mathrm{yr}\right)$ of primary energy, the high education campus is shown to be around two times more energy consuming.

Concerning comfort, results show important thermal and air quality discomforts during the three evaluated seasons. For instance, important overheating phenomena have been identified in classrooms and, even if less intense, in offices according to the frequency distribution of PMV. This result, combined to the poor air quality, can explain the need of ventilation.

One of the main results of the audit concern the inadequate energy management system.

Occupation schemes of such campuses are directly linked to teaching activities. We can distinguish weekdays/weekends, class periods/holidays, day/night, etc. The energy management system should be able to control the indoor environment to a comfortable level during occupation periods. At the same time, the system should be turned into energy saving mode during non-occupation. This way, the double objective of thermal comfort and energy efficiency could be possible. 
According to the energy systems diagnostic results, the energy saving mode is not used in general. For instance, almost all heating floor substations operate according to the same heating curve around the clock.

The ventilation system study reveals similar results: the AHU keep ventilating the building during weekends and nights. This strategy is adopted by the building energy manager to ensure the set point temperature at 8 am during opening days, and during very cold days in particular. Our simulations showed that this strategy can be optimized. Some recommendations in this direction were proposed to the building energy manager.

On the other hand, the thermal comfort assessment shows an overheating and poor air quality in most of cases. The recommendation is thus to use an energy saving mode during holidays while maintaining a comfortable environment during class periods by increasing ventilation rates to ensure indoor air quality and avoid overheating due to the occupancy.

Moreover, a big variety of room occupancies/uses was observed. Half of the space is used as classrooms where human thermal gains can quickly compensate heating needs. The other half space is dedicated to office uses with a much lower occupancy. In this case, an individual control system would be quite advantageous not only to guarantee a varied indoor environment but also to reduce heating consumption, mainly in classrooms during occupancy.

The study of ventilation system and comfort questionnaires confirmed this assumption. According to the ventilation system diagnostic, the air exchange rate is not sufficient for a classroom when the mechanical ventilation is exclusively used. In this case, most students, according to the comfort and behaviour questionnaire, would open the windows to enhance air natural ventilation. On the other hand, offices occupants would prefer higher temperatures than those calculated by PMV and frequently use additional heaters to reach this goal. A different regulation of the heating system distribution for offices and classrooms and a differentiation of the thermal management and control strategies for these two areas can provide a better comfort without handing down the control of local thermal energy devices to end users.

As explained in point 3.1, the context of our study is different from a typical energy audit done by a service company. We had the time to test and experiment a transverse and crossdisciplinary approach, including deep investigation of the building and energy systems features as well as the occupants' comfort. This allowed us to test different methods in the field. We tried to cross these methods by adopting (and adapting) them from codified norms and international standards. We aim now at highlighting the encountered difficulties. 
The first step of inspection and documentation was quite straightforward since the study was done on a campus of the institution of some of the authors. However, some data, such as the heating fluids flow rates in different key point of the networks, were impossible to obtain since the heating and ventilation systems were not sufficiently instrumented. Their experimental determination required long measurement campaigns. This was also the case for other key parameters for the BEM such as the building's thermal mass and U-value. If a first estimation of U-value could be calculated from the data given in the plans, this was not the case for the thermal mass.

Finally, the development of the BEM and its validation was very time consuming which is a real obstacle towards the generalization of this tool in commercial audit protocols. The relevance of such a tool is to be evaluated with respect to the expected benefits for each specific case. For the present case study, a set of recommendations regarding energy management strategies obtained through numerical simulations are going to be implemented by the building energy manager. The experimental results would allow us to evaluate the interest of BEM development for the present case.

It is worth noting that the complexity of the considered case study is not fully addressed by the present work. Indeed, a representative sample with respect to occupation and the main activities (administration and teaching) was chosen for instrumentation and modelling. However, this sample is not representative with respect to energy consumption shares of the different parts of the building. Indeed, the largest energy consumption shares are due to very specific processes such as those used in the clean rooms, the datacenters and the canteens which fall outside the scope of control of the building energy manager.

Concerning the comfort investigation, bridging the gap between the theory and the practice of an operational and professional work reveals to be an ambitious goal. The consequence is a difficulty in transposing the indications from international standards to the specific characteristics of the context. It was for example not possible to use the PMV in all situations because of the non-stationary environmental conditions. This limits the application scope of the PMV indicator. The variability of mid-season climate (April) raises the same type of questions. Another critical point concerns the survey. 


\section{Conclusions}

This case study dealt with a detailed energy audit over a campus building. The implemented methodology is different from common protocols of energy audit usually adopted by service companies in that:

i. We combined thermal comfort questionnaires, air indoor quality evaluation and the building energy systems audit. In this way, we have been able to apprehend the buildingsystem as a whole (technique + management + occupants). Such a simultaneous processing of these different aspects allows us to overcome the comfort vs energy efficiency dilemma. Indeed, in some cases, it paradoxically appears that some phenomena simultaneously induce discomfort and an increase of energy consumption. Addressing them by the appropriate recommendation can increase the comfort and reduce the energy consumption at the same time. The energy management system upgrade, by integrating an automatic control solution for example, appears to be the most important and effective measure among the different retrofitting recommendations. This retrofitting should be very cost effective since it requires very low investments.

ii. A detailed BEM was developed. It can give precise predictions of the energy efficiency of some recommendations, particularly on efficient building preheating strategies after non occupation periods (weekends and holidays). Some proposed and simulated strategies were validated by the building energy manager for future implementation.

iii. Finally, our transverse approach allowed us to obtain a complete and complementary view of the building and its operating conditions. However, the specificity of the case study and the detail level of some tasks and the material and human resources allocated for the implementation of the proposed audit protocol keep it far from " ready to use » protocols. Indeed, capturing the full complexity of a building-system (building energy devices+ management strategies + occupancy and behaviours impact) needs a widebreathe approach and invites us to beware of the limits of key-in-hand audits and solutions. 


\section{Acknowledgements}

Authors would like to thank the following Master's students which greatly contributed to the present work: Arinaly Ralahy, Riccardo Calegari and Soufiane Acoudad. They also thank Pierre Picard and Bruno Dalmais for fruitful discussions and the administration of the case study institution for active collaboration in implementing the required experiments. The present study was supported by Efficacity.

\section{References}

[1] F. R. A. Alfano, L. Bellia, A. Boerstra, F. van Dijken, E. Ianniello, G. Lopardo, et al., Indoor Environment and Energy Efficiency in Schools. Part 1: Principles, REHVA Guidebook NO 13, 2010.

[2] D. Zanni, A. Righi, T. Dalla, F. Peron, The Energy improvement of school buildings : analysis and proposals for action, Energy Procedia 82 (2015) 526-532. doi:10.1016/j.egypro.2015.11.865.

[3] L.T. Wong, K.W. Mui, P.S. Hui, A multivariate-logistic model for acceptance of indoor environmental quality (IEQ) in offices, Building and Environment. 43 (2008) 1-6. doi:10.1016/j.buildenv.2007.01.001.

[4] S.A. Ghita, T. Catalina, Energy efficiency versus indoor environmental quality in different Romanian countryside schools, Energy and Buildings. 92 (2015) 140-154. doi:10.1016/j.enbuild.2015.01.049.

[5] L. Dias Pereira, D. Raimondo, S.P. Corgnati, M. Gameiro da Silva, Energy consumption in schools - A review paper, Renewable and Sustainable Energy Reviews. 40 (2014) 911922. doi:10.1016/j.rser.2014.08.010.

[6] T.G. Theodosiou, K.T. Ordoumpozanis, Energy, comfort and indoor air quality in nursery and elementary school buildings in the cold climatic zone of Greece, Energy and Buildings. 40 (2008) 2207-2214. doi:10.1016/j.enbuild.2008.06.011.

[7] Renew school project website: www.renew-school.eu

[8] Alliance to save energy website: $w w w$.ase.org

[9] D.F. Motta Cabrera, H. Zareipour, Data association mining for identifying lighting energy waste patterns in educational institutes, Energy and Buildings. 62 (2013) 210-216. doi:10.1016/j.enbuild.2013.02.049.

[10] L. Lan, P. Wargocki, Z. Lian, Quantitative measurement of productivity loss due to thermal discomfort, Energy and Buildings. 43 (2011) 1057-1062.

doi:10.1016/j.enbuild.2010.09.001.

[11] M.J. Mendell, W.J. Fisk, K. Kreiss, H. Levin, D. Alexander, W.S. Cain, et al., Improving the health of workers in indoor environments: priority research needs for a national occupational research agenda., American Journal of Public Health. 92 (2002) 1430-40. doi:10.2105/AJPH.92.9.1430. 
[12] P. Wargocki, O. Seppänen, Indoor climate and productivity in offices, REHVA Guidebook NO 6, 2006.

[13] M. El Asmar, A. Chokor, I. Srour, Are building occupants satisfied with indoor environmental quality of higher education facilities?, Energy Procedia. 50 (2014) 751760. doi:10.1016/j.egypro.2014.06.093.

[14] M. Raatikainen, J.-P. Skön, K. Leiviskä, M. Kolehmainen, Intelligent analysis of energy consumption in school buildings, Applied Energy. 165 (2016) 416-429. doi:10.1016/j.apenergy.2015.12.072.

[15] M.N.M. Salleh, M.Z. Kandar, S.R.M. Sakip, Benchmarking for Energy Efficiency on School Buildings Design : A review, Procedia - Social and Behavioral Sciences. 222 (2016) 211218. doi:10.1016/j.sbspro.2016.05.149.

[16] Mairie de Paris-Direction des Espaces Verts et de l'Environnement- Agence d'Ecologie Urbaine-Division Climat-Energie, Rénovation énergétique des écoles parisiennes (2014) $1-2$.

[17] A. Thewes, S. Maas, F. Scholzen, D. Waldmann, A. Zürbes, Field study on the energy consumption of school buildings in Luxembourg, Energy and Buildings. 68 (2014) 460470. doi:10.1016/j.enbuild.2013.10.002.

[18] V. Butala, P. Novak, Energy consumption and potential energy savings in old school buildings, Energy and Buildings. 29 (1999) 241-246. doi:10.1016/S0378-7788(98)00062-0.

[19] E.G. Dascalaki, V.G. Sermpetzoglou, Energy performance and indoor environmental quality in Hellenic schools, Energy and Buildings. 43 (2011) 718-727. doi:10.1016/j.enbuild.2010.11.017.

[20] D. Agdas, R.S. Srinivasan, K. Frost, F.J. Masters, Energy use assessment of educational buildings: Toward a campus-wide sustainable energy policy, Sustainable Cities and Society. 17 (2015) 15-21. doi:10.1016/j.scs.2015.03.001.

[21] V.I. Deshko, O.M. Shevchenko, University campuses energy performance estimation in Ukraine based on measurable approach, Energy and Buildings. 66 (2013) 582-590. doi:10.1016/j.enbuild.2013.07.070.

[22] M. Turunen, O. Toyinbo, T. Putus, A. Nevalainen, R. Shaughnessy, U. HaverinenShaughnessy, Indoor environmental quality in school buildings, and the health and wellbeing of students, International Journal of Hygiene and Environmental Health. 217 (2014) 733-739. doi:10.1016/j.ijheh.2014.03.002.

[23] M.C. Lee, K.W. Mui, L.T. Wong, W.Y. Chan, E.W.M. Lee, C.T. Cheung, Student learning performance and indoor environmental quality (IEQ) in air-conditioned university teaching rooms, Building and Environment. 49 (2012) 238-244. doi:10.1016/j.buildenv.2011.10.001.

[24] P. Wargocki, D.P. Wyon, Providing better thermal and air quality conditions in school classrooms would be cost-effective, Building and Environment. 59 (2013) 581-589. doi:10.1016/j.buildenv.2012.10.007.

[25] R. Becker, I. Goldberger, M. Paciuk, Improving energy performance of school buildings while ensuring indoor air quality ventilation, Building and Environment. 42 (2007) 32613276. doi:10.1016/j.buildenv.2006.08.016.

[26] G.J. Besler, M. Besler, Towards healthy microclimate of closed spaces and habitats, 
Environment Protection Engineering. 26 (2000) 23-38.

[27] O. Seppänen, W. Fisk, Q. Lei, Effect of Temperature on Task Performance in Office Environment, Lawrence Berkeley National Laboratory. (2006) 11.

[28] M. El Mankibi, Indoor air quality control in case of scheduled or intermittent occupancy based building: Development of a scale model, Building and Environment. 44 (2009) 1356-1361. doi:10.1016/j.buildenv.2008.06.003.

[29] D. H. Mudarri, Potential correction factors for interpreting $\mathrm{CO} 2$ measurements in buildings, ASHRAE Transactions 103(2) (1997) 244-255.

[30] U. Satish, M.J. Mendell, K. Shekhar, T. Hotchi, D. Sullivan, S. Streufert, et al., Is CO2 an indoor pollutant? Direct effects of low-to-moderate CO2 concentrations on human decision-making performance, Environmental Health Perspectives. 120 (2012) 16711677. doi:10.1289/ehp.1104789.

[31] P.O. Fanger, B. Berg-Munch, Ventilation and body odour, Proceedings of Enclosed Spaces Conference (1983) ASHRAE, 45-50, Atlanta.

[32] G. Clausen, Sensory evaluation of emission and indoor air quality, Proceedings of Healthy Buildings, vol1 (2000) 53-62, Espoo, Finland.

[33] Z. Bakó-Biró, D.J. Clements-Croome, N. Kochhar, H.B. Awbi, M.J. Williams, Ventilation rates in schools and pupils' performance, Building and Environment. 48 (2012) 215-223. doi:10.1016/j.buildenv.2011.08.018.

[34] D. Teli, M.F. Jentsch, P.A.B. James, Naturally ventilated classrooms: An assessment of existing comfort models for predicting the thermal sensation and preference of primary school children, Energy and Buildings. 53 (2012) 166-182.

doi:10.1016/j.enbuild.2012.06.022.

[35] D. Mumovic, J. Palmer, M. Davies, M. Orme, I. Ridley, T. Oreszczyn, et al., Winter indoor air quality, thermal comfort and acoustic performance of newly built secondary schools in England, Building and Environment. 44 (2009) 1466-1477. doi:10.1016/j.buildenv.2008.06.014.

[36] S.P. Corgnati, R. Ansaldi, M. Filippi, Thermal comfort in Italian classrooms under free running conditions during mid seasons: Assessment through objective and subjective approaches, Building and Environment. 44 (2009) 785-792.

doi:10.1016/j.buildenv.2008.05.023.

[37] P. Wargocki, Ventilation, indoor air quality and learning in schools, Proceedings of the 36th AIVC conference, 2015, Madrid.

[38] G. Smedje, D. Norbäck, New ventilation systems at select schools in Sweden--effects on asthma and exposure, Archives of Environmental Health. 55 (2000) 18-25. doi:10.1080/00039890009603380.

[39] I. Sarbu, C. Pacurar, Experimental and numerical research to assess indoor environment quality and schoolwork performance in university classrooms, Building and Environment. 93 (2015) 141-154. doi:10.1016/j.buildenv.2015.06.022.

[40] S.B. Riffat, K.W. Cheong, Estimation of zone effective-volume using tracer-gas techniques, Applied Energy. 45 (1993) 327-334. doi:10.1016/0306-2619(93)90004-9.

[41] ASTM, ASTM E741-11 Standard Test Method for Determining Air Change in a Single Zone 
by Means of a Tracer Gas Dilution, ASTM International. 0 (2011) 1-18. doi:10.1520/E0741-11.Copyright.

[42] M.H. Sherman, Tracer-gas techniques for measuring ventilation in a single zone, Building and Environment. 25 (1990) 365-374. doi:10.1016/0360-1323(90)90010-0.

[43] M. Sandberg, What is ventilation efficiency?, Building and Environment. 16 (1981) 123135. doi:10.1016/0360-1323(81)90028-7.

[44] NT VVS 019, Building Ventilation air: Local mean age, Edition 2 (1988) 11, Espoo, Finland.

[45] H. Han, Ventilation effectiveness measurements using tracer gas technique, Fluid Dynamics, Computational Modeling and Applications. (2012) 41-66.

[46] H. Chappells, E. Shove, Debating the future of comfort: environmental sustainability, energy consumption and the indoor environment, Building Research \& Information. 33 (2005) 32-40. doi:10.1080/0961321042000322762.

[47] H. Wilhite, E. Shove, L. Lutzenhiser, W. Kempton, Twenty years of energy demand management: we know more about individual behavior but how much do we really know about demand, ACEEE Summer Study on Energy Efficiency in Buildings. (2000) 435-453. doi:10.1007/0-306-48160-X.

[48] F. Nicol, M. Humphreys, et.S. Roaf, Adaptive Thermal Comfort: Principles and Practice, Routledge, Earthscan, London, 2012.

[49] M. Humphreys, F. Nicol, et.S. Roaf, Adaptive Thermal Comfort: Foundations and Analysis, Routledge, Earthscan, London, 2015.

[50] R.F. Rupp, N.G. Vasquez, R. Lamberts, A review of human thermal comfort in the built environment, Energy and Buildings. 105 (2015) 178-205. doi:10.1016/j.enbuild.2015.07.047.

[51] J. Malchaire, Human thermal environments: The effects of hot, moderate and cold environments on human health-comfort and performance: The principles and the practice, Safety Science. 18 (1994) 67-68. doi:10.1016/0925-7535(94)90046-9.

[52] A. Lenoir, S. Cory, M. Donn, F. Garde, Users' behavior and energy performances of net zero energy buildings, Proceedings of Building Simulation (2011) 14-16.

[53] J. Toftum, R. V. Andersen, K.L. Jensen, Occupant performance and building energy consumption with different philosophies of determining acceptable thermal conditions, Building and Environment. 44 (2009) 2009-2016. doi:10.1016/j.buildenv.2009.02.007.

[54] M. Pellegrino, M. Simonetti, G. Chiesa, Reducing thermal discomfort and energy consumption of Indian residential buildings: Model validation by in-field measurements and simulation of low-cost interventions, Energy and Buildings. 113 (2016) 145-158. doi:10.1016/j.enbuild.2015.12.015.

[55] NF EN 15251 (août 2007) : Critères d'ambiance intérieure pour la conception et évaluation de la performance énergétique des bâtiments couvrant la qualité de l'air intérieur, la thermique, l'éclairage et l'acoustique (Indice de classement : E5, 15251 (2013).

[56] B.S.E.N. Iso, Ergonomics of the thermal environment - Estimation of thermal insulation and water vapor resistance of a clothing ensemble (ISO $9920: 2007$, Corrected version 2008-11-01), Management. (2009). 
[57] NF EN ISO 7730 (mars 2006) : Ergonomie des ambiances thermiques - Détermination analytique et interprétation du confort thermique par le calcul des indices PMV et PPD et par des critères de confort thermique local (Indice de classement : X35-203) Ce d, 7730 (2013).

[58] I. Standard, ISO 7726 Ergonomics of the thermal environment - Instruments for measuring physical quantities, ISO Standard. 1998 (1998) 1-56. doi: ISO 7726:1998 (E).

[59] NF EN ISO 10551 : Ergonomie des ambiances thermiques - Evaluation de l'influence des ambiances thermiques à l'aide d'échelles de jugements subjectifs Ce d, 10551 (2001). 